OAK RIDGE

NATIONAL

LABORATORY

LOCKHEED WARTIN

\section{Distributed Monitoring System for Electric-Motor- Driven Compressors}

\author{
K. N. Castleberry
}


This report has been reproduced directly from the best available copy.

Available to DOE and DOE contractors trom the Office of Scientific and Technical Information, P.O. Box 62, Oak Ridge, TN 37831; prices available from (423) -576-8401, FTS 626-8401.

Available to the public from the National Technical Information Service, U.S. Department of Commerce, 5285 Port Royal Rd., Springfield, VA 22161.

This report was prepared as an account of work sponsored by an agency of the United States Government. Neither the United States Government nor any agency thereof, nor any of their employees, makes any warranty, express or implied, or assumes any legal liability or responsibility for the accuracy, completeness, or usefulness of any information, apparatus, product, or process disclosed, or represents that its use would not infringe privately owned rights. Reference herein to any specific commercial product, process, or service by trade name, trademark, manufacturer, or otherwise, does not necessarily constitute or imply its endorsement, recommendation, or favoring by the United States Government or any agency thereof. The views and opinions of authors expressed herein do not necessarily state or reflect those of the United States Government or any agency thereof. 
Instrumentation and Controls Division

\title{
DISTRIBUTED MONITORING SYSTEM FOR ELECTRIC-MOTOR-DRIVEN COMPRESSORS
}

K. N. Castleberry

Date Published - January 1996

\author{
Prepared by \\ OAK RIDGE NATIONAL LABORATORY \\ Oak Ridge, Tennessee 37831-6285 \\ managed by \\ LOCKHEED MARTIN ENERGY RESEARCH CORP. \\ for the \\ U. S. DEPARTMENT OF ENERGY \\ under contract DE-AC05-96OR22464
}




\section{CONTENTS}

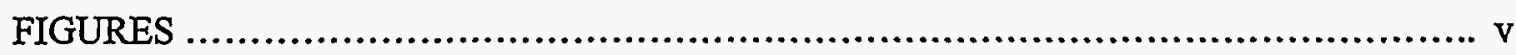

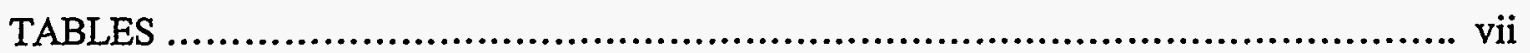

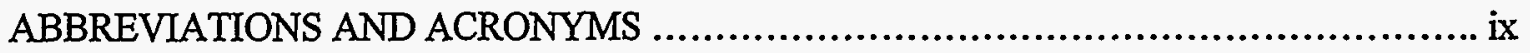

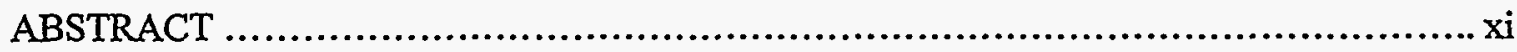

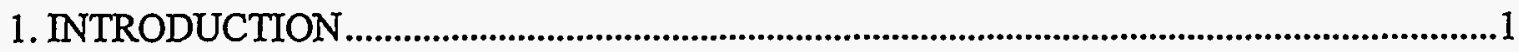

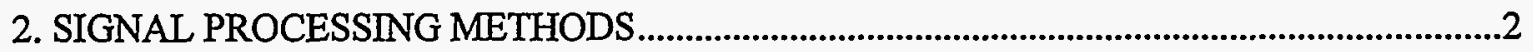

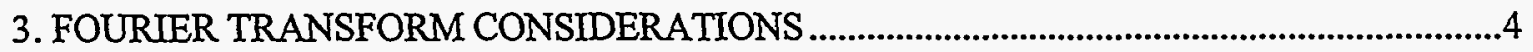

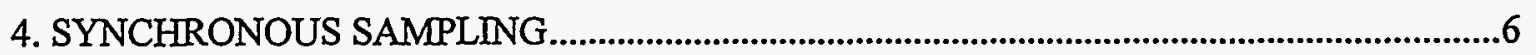

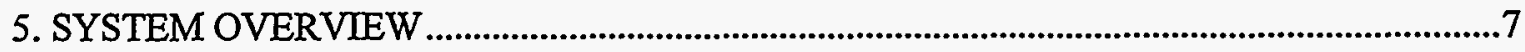

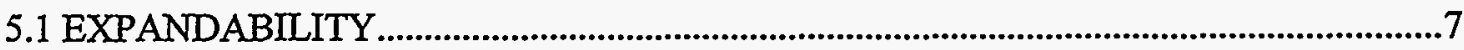

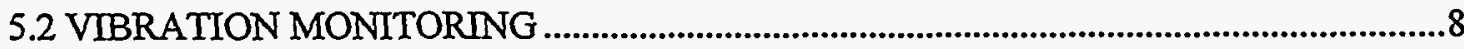

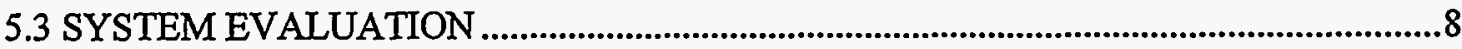

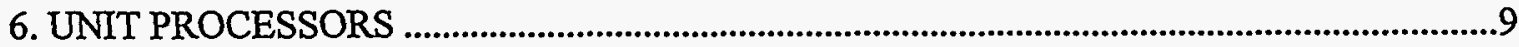

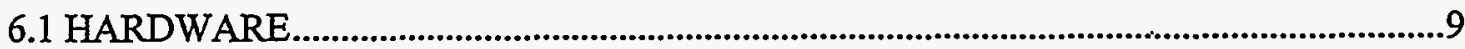

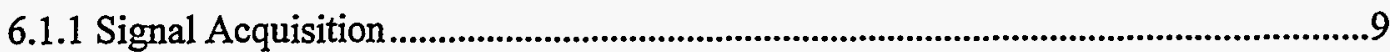

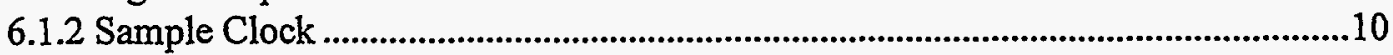

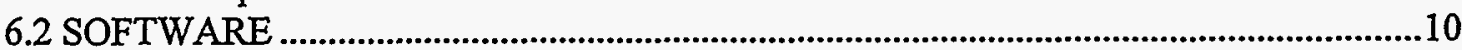

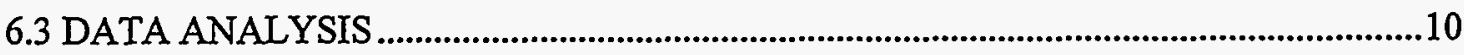

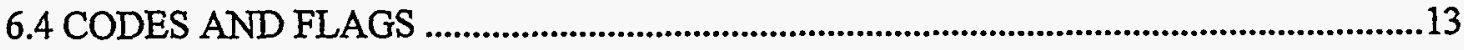

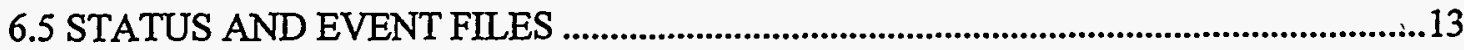

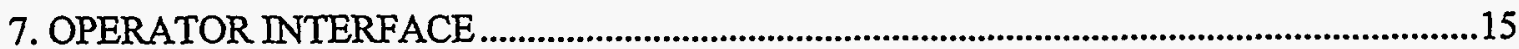

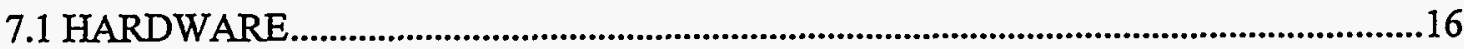

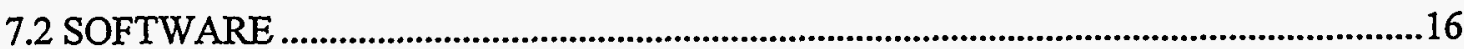

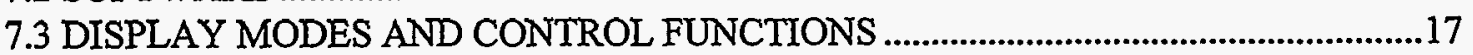

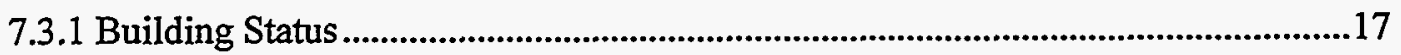

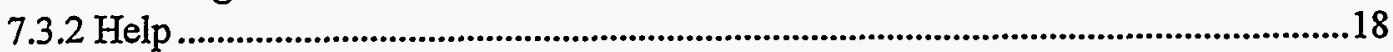

7.3.3 Cell Data Screen...................................................................................................19

7.3.4 FFT Spectrum Screen.............................................................................................19

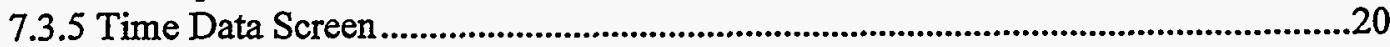

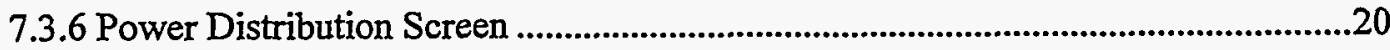

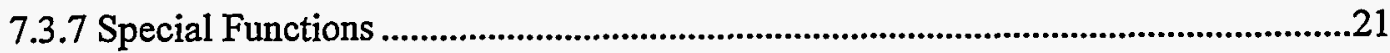

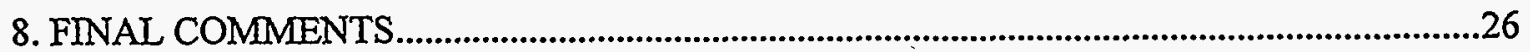

APPENDIX A: SYSTEM HARDWARE ............................................... 27 
APPENDIX B: MULTIPLEXER INPUT WIRING 


\section{FIGURES}

Figure

Page

Fig. 3.1. Nonsynchronous spectrum with display gain equal to one. ..........................................4

Fig. 3.2. Nonsynchronous spectrum with display gain equal to 100 ..............................................5

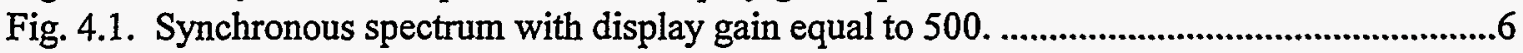

Fig. 5.1. Demonstration system configuration...........................................................................

Fig. 6.1. Synchronous sample clock schematic. ....................................................................11

Fig. 6.2. Fast Fourier transform for a typical 000-size motor...................................................12

Fig. 7.1. Record Unit Time Data screen..................................................................................15

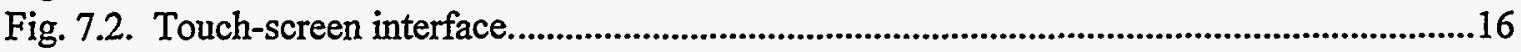

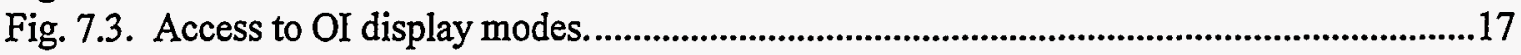

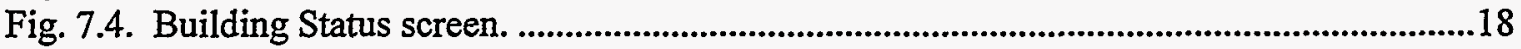

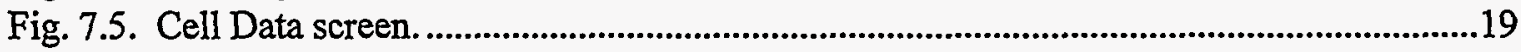

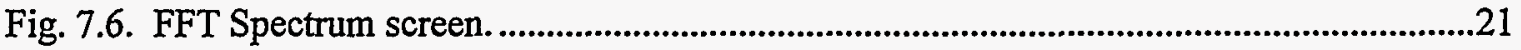

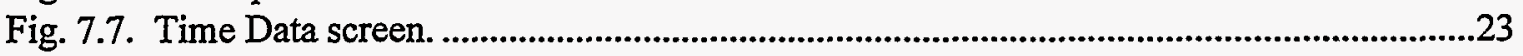

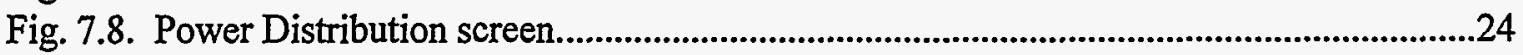

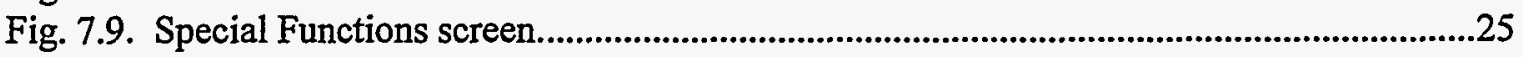

Fig. A.1 Multiplexer board mounting configuration (top view)................................................30

Fig. A.2 COM cable wiring..............................................................................................................31

Fig. B.1 Typical cabling configuration (CT to multiplexer).......................................................35 
. 


\section{TABLES}

Table

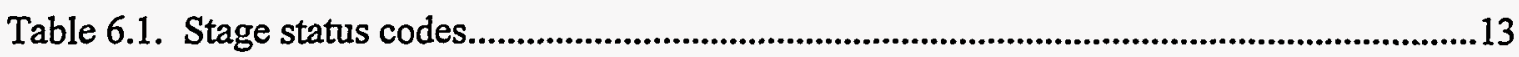

Table 7.1. Building Status screen function buttons ....................................................................18

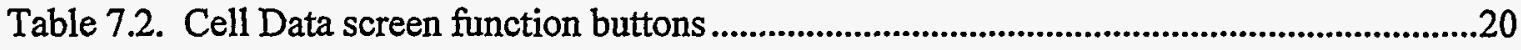

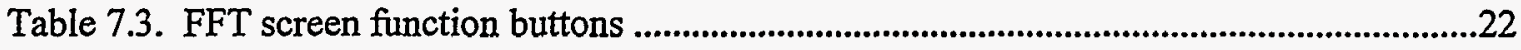

Table 7.4. Time Data screen function buttons ...................................................................23

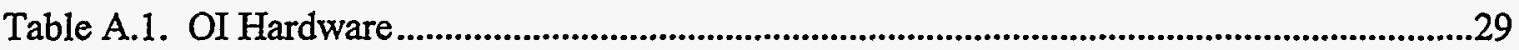

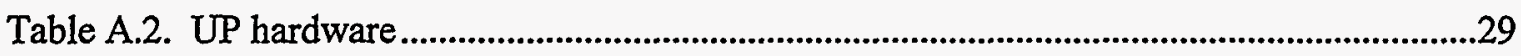

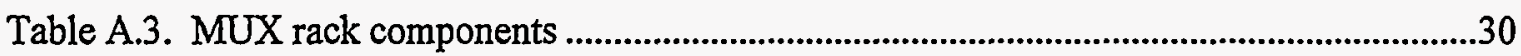

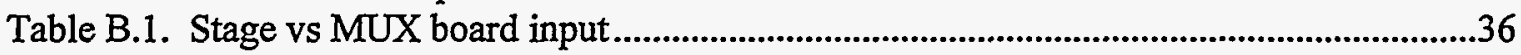

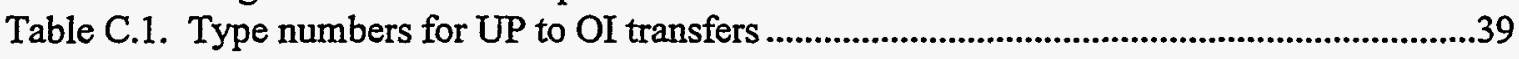

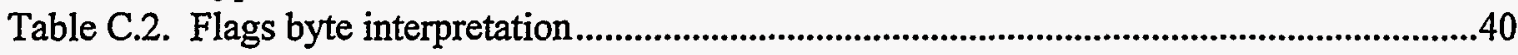

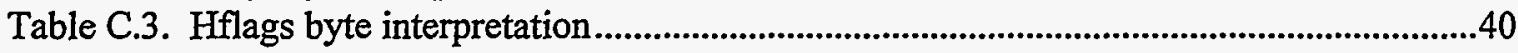

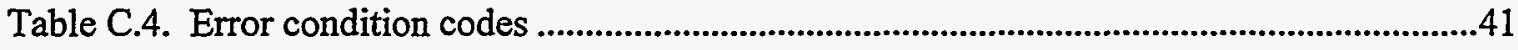

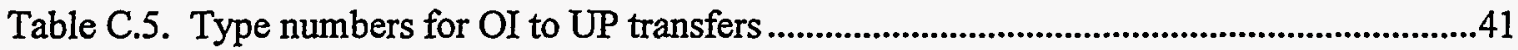


. 


\begin{abstract}
Personnel in the Instrumentation and Controls Division at the Oak Ridge National Laboratory, in association with the United States Enrichment Corporation (USEC), the Navy, and various Department of Energy sponsors, have been involved in the development and application of motor-current signature analysis (CSA) for several years. In that time CSA has proven to not only be useful for manually applied periodic monitoring of electrically driven equipment, but it has also been demonstrated to be well suited for dedicated monitoring systems in industrial settings. Recent work has resulted in the development and installation of a system that can monitor up to 640 motor and compressor stages for various aerodynamic conditions in the gas compressors and electrical problems in the drive motors. This report describes a demonstration of that technology installed on 80 stages at each of the two USEC uranium enrichment plants.
\end{abstract}




\section{INTRODUCTION}

Since 1987, personnel from the Instrumentation and Controls Division of the Oak Ridge National Laboratory (ORNL) have been investigating and developing current-signature-analysis (CSA) techniques for identifying problems and abnormal operating conditions in electric-motordriven equipment. CSA has been shown to be useful in the diagnosis of many conditions not normally thought to be observable by examination of the motor current, and many load-related problems have actually been found to be more easily detected with CSA than with any other single-sensor means.

Part of the Oak Ridge National Laboratory (ORNL) work has involved studies of motors and compressors used in the United States Enrichment Corporation (USEC) processing facilities located at Portsmouth, Ohio, and Paducah, Kentucky. These plants employ cascades of many hundreds of gas-compressor stages driven by motors ranging in size from 100 to $3300 \mathrm{hp}$. In the monitoring of such equipment, CSA has demonstrated the ability to provide information that not only includes motor problems and compressor-aerodynamic instabilities but also coupling misalignment and rotational imbalances, which cause most vibration problems. 1

In the X300 building at the Portsmouth Gaseous Diffusion Plant (PORTS), 00-size compressor failures due to an instability known as rotating stall or secondary have been essentially eliminated during the past year by a CSA-based secondary monitor. This particular system was installed a few years ago and does not employ the latest processing techniques, but it illustrates how CSA can be used for dedicated monitoring. Advances in the field have been rapid, and more recent system capabilities, which are the focus of this report, can far exceed those of the 00 Secondary Monitor.

1 S. F. Smith and K. N. Castleberry, "Advanced Techniques in Current Signature Analysis," pp. 63-75 in Proceedings of the 46th Meeting of the Mechanical Failures Prevention Group, Virginia Beach, VA, April 7-9, 1992. 


\section{SIGNAL PROCESSING METHODS}

CSA encompasses a number of techniques, which all basically use the presence and amplitude of various frequency components in a motor current to derive condition information about both the motor and the driven load. These frequency components result from variations in the motor load that cause comparable variations or modulations in the amplitude and phase of the fundamental $60-\mathrm{Hz}$ line frequency. Most of the published work in CSA by Oak Ridge researchers and others has depended heavily on analog signal processing schemes, which allow low-level modulations to be extracted from the main load current so they can be amplified and analyzed. Typical processing methods include assorted filter configurations, which act to remove high-level signals such as the 60-Hz line frequency, and demodulation techniques, which acquire the load variation signals in much the same way that music is extracted from an AM or FM radio signal. After recovery by either technique, the load-related signal is typically amplified by a factor of 100 or more before being fed to either a spectrum analyzer or to a computer, where it is digitally sampled and subsequently broken down into its fundamental frequency components. These methods can allow signals that are as much as $80 \mathrm{~dB}$ below the amplitude of the main $60-\mathrm{Hz}$ signal to be recovered and examined.

A notable problem is encountered with the way demodulation methods handle lowfrequency modulation components below about $5 \mathrm{~Hz}$, such as the motor slip. These frequencies are usually attenuated to some degree by the capacitive coupling placed between signal processing stages. In the analysis process, low-frequency components are very important in diagnosing certain motor-related problems, and any attenuation can result in significant errors. Such low-frequency attenuation can be overcome by the elimination of any capacitive coupling, although the resulting dc-coupled circuitry comes with its own set of unique problems, such as dealing with an unwanted dc-signal component.

A characteristic of most CSA preprocessing is that in the quest to attenuate or eliminate the large $60-\mathrm{Hz}$ component, other frequencies of interest can also be attenuated or eliminated. Perhaps the main disadvantage in preprocessing the current signals with filters or demodulation before digitization and analysis is that an important reference, the amplitude of the total current, is lost. Without a measurement of the original amplitude, it is difficult to accurately quantify the intensity of a recovered modulation component. A magnitude reading can, of course, be obtained separately from the original signal, but it requires additional hardware and processing. Another technique, often referred to as wide-band analysis, uses direct sampling of a motor current without significant preprocessing to overcome many of the inherent problems introduced by either filtering or demodulation. While this technique provides wide bandwidth without frequency-dependent attenuation problems, the sensitivity to very low level modulations has typically been much less than obtainable with preprocessing methods. This has been due to the limited dynamic range provided by most laboratory-grade spectrum analyzers or 12-bit analogto-digital (A/D) conversion hardware available for computer-based applications. In the last couple of years, however, the increased availability and decreased cost of high-resolution 16-bit A/D converter boards for personal computers (PCs) has significantly extended the low-level range of wide-band analysis. As a result, it is becoming the preferred method for dedicated monitoring.

Wide-band analysis also benefits from the fact that the bandwidth of the signal spectrum to be examined can be controlled by changing the sample rate for the $A / D$ conversion process. This applies equally to signal analysis with a spectrum analyzer or computer-based hardware although 
most spectrum analyzers do not allow selection of another important sampling parameter, the number of sample points. After sampling in a computer-based application, a discrete Fourier transform (DFT) of the sampled signal is usually calculated to break the signal into its constituent frequency components. The frequency resolution or the distance in frequency space between adjacent spectral lines in the resulting DFT is a function of both the sample rate and the number of sample points. 


\section{FOURIER TRANSFORM CONSIDERATIONS}

A Fourier transform is a trigonometric series that provides a mathematical solution to certain problems that can be expressed as partial differential equations. When used in signal analysis, it is a mathematical tool of the form

$$
F(w)=\int_{-\infty}^{\infty} f(t) e^{-j w t} d t
$$

that resolves a real signal, $f(t)$, into its exponential components. The result can then be expanded into a series involving sines and cosines, which represent the relative amplitudes of the frequency components that compose $f(t)$. The DFT is a derivation of the above form, which allows a Fourier transform to be applied in digital signal processing. Thus the DFT provides a means for transforming a finite record of data samples into a finite group of frequency domain components.

While the frequency range and bandwidth of a DFT can be controlled by adjusting the sample rate and number of sampled points, other considerations can seriously affect the range of recoverable components in a calculated DFT. The sample rate is generally determined based almost entirely on the desired bandwidth of the final transform, but without special treatment, almost any sample rate will result in spreading of the spectral energy from large frequency components, like the $60-\mathrm{Hz}$ line frequency in a motor current signal, into many adjacent DFT bins or spectral lines. Figure 3.1 shows a spectral plot from a typical motor current sampled at $480 \mathrm{~Hz}$. Here, only the $60-\mathrm{Hz}$ component is visible, but when the vertical-axis gain is increased by a factor of 100 (Fig. 3.2), one finds that the 60-Hz energy has spread into a large skirt around the main peak. It is not obvious from the plot whether or not this spreading is real, but it effectively masks any low-level components that might exist there. The spreading is actually an artifact of the transform process, resulting in part from inconsistent sample placement in successive cycles of the incoming signal.

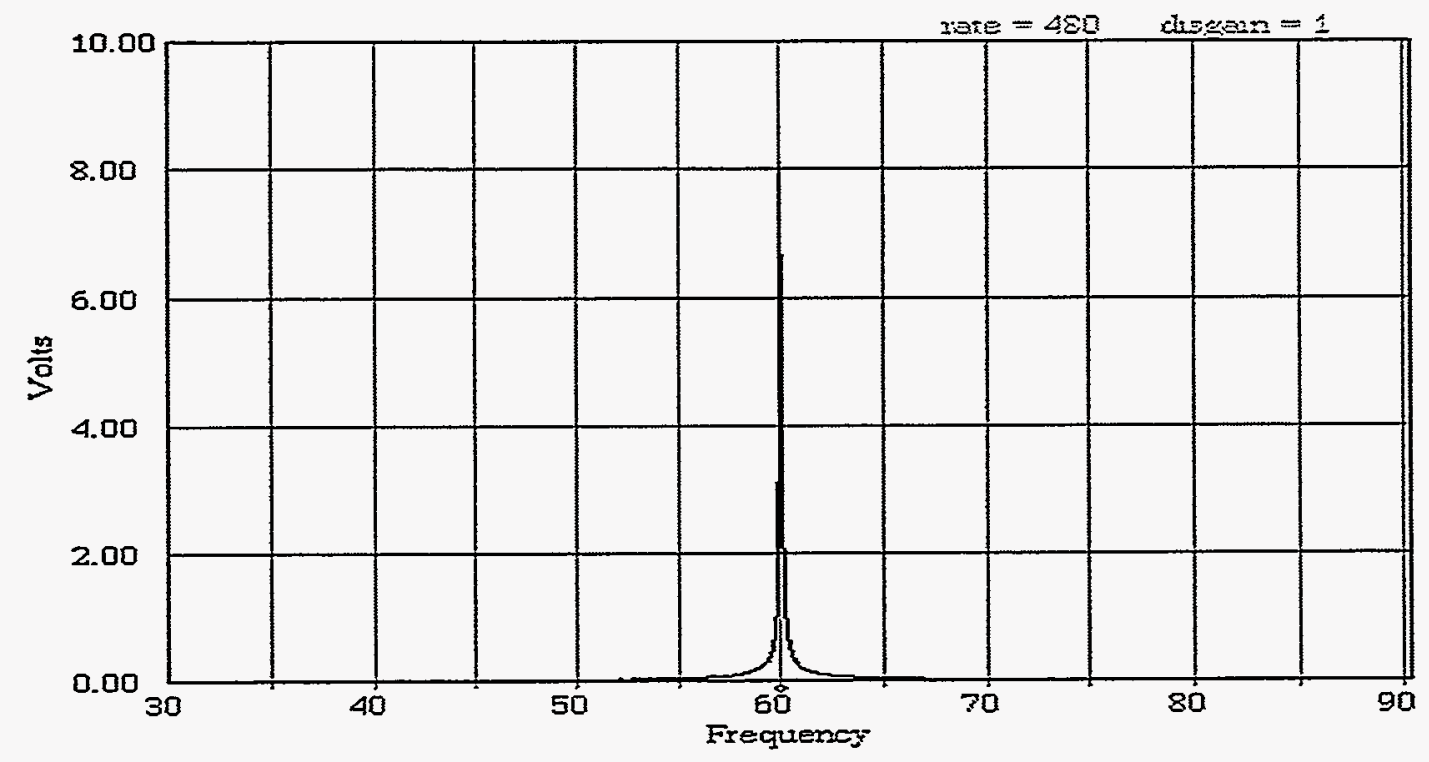

Fig. 3.1. Nonsynchronous spectrum with display gain equal to one. 


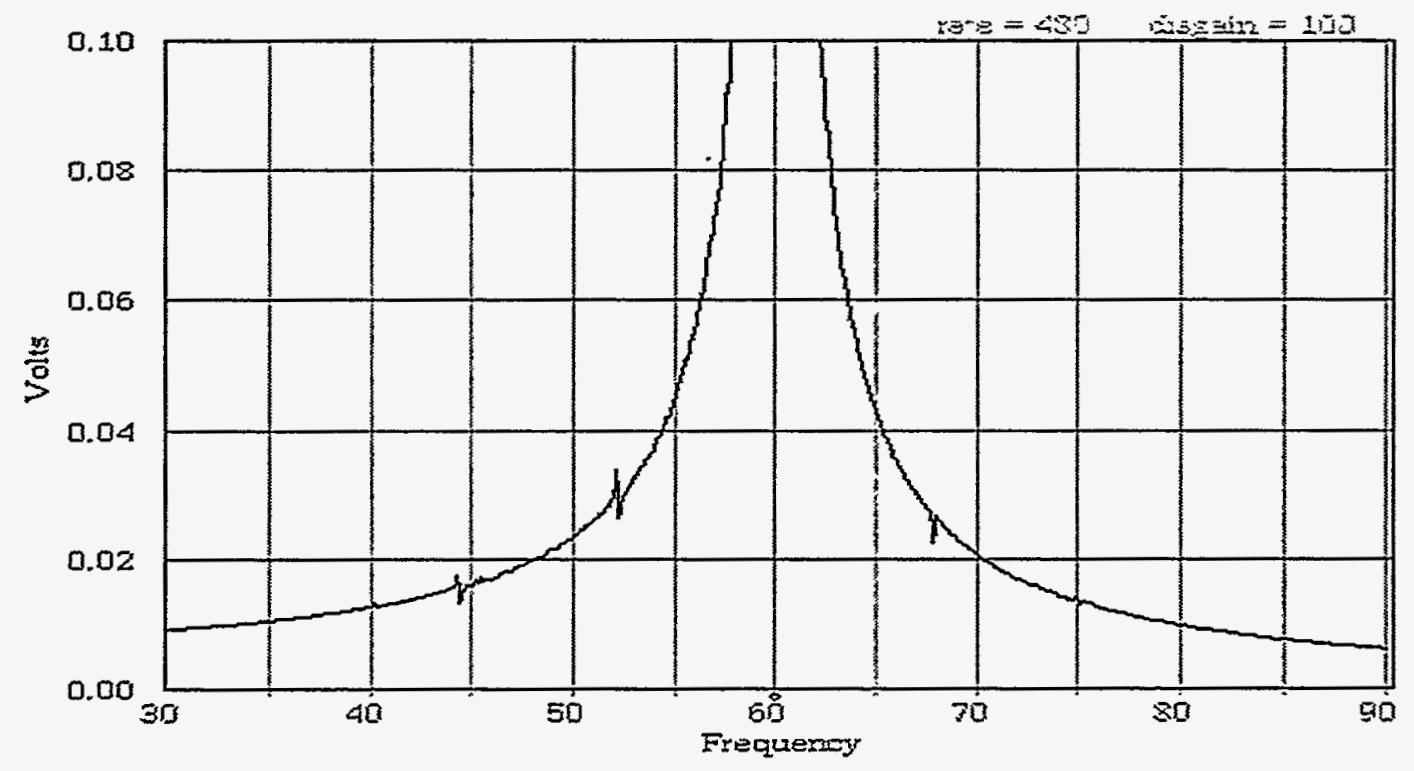

Fig. 3.2. Nonsynchronous spectrum with display gain equal to 100 .

Another view of this problem is found in the study of windowing of DFT data sets to reduce leakage or cross-talk between adjacent lines in the DFT output. Although in general a premultiplication of the data set by a special "windowing" function is employed to control the spectral interbin leakage, application of certain constraints on the sampling process is usually much more effective. If the actual signal from which the sample frame is taken is periodic and if the duration of the frame period is an integral multiple of the primary signal period, then windowing actually becomes unnecessary. In other words, if the data record contains exactly an integer number of cycles of the original signal and if there is exactly an integer number of samples per cycle, analysis errors are minimized in all respects.

The DFT may by definition contain any integral number of points, $N$, even if $N$ is prime. Such a DFT is generally termed an " $N$-point DFT" and is quite complex to implement. Since the basic DFT requires on the order of $N^{2}$ complex operations for an $N$-point transform, numerous researchers have labored to simplify the calculation of the DFT because of its importance in digital signal processing applications. The calculation time for large- $N$ DFTs can be long (i.e., a 1024-point DFT requires greater than 1 million complex math operations). For the special case where $N$ is an integer power of 2, a specially optimized sequence of computations to extract the DFT values is referred to as the fast Fourier transform (FFT). The computation time for the FFT is, in general, much faster than for the standard DFT, because only $N \times \log _{2}(N)$ calculations are required. For $N=1024$ points, this represents a 100-fold improvement in processing speed. Thus, it is apparent that an ideal transform size is $N=2 r$, where $r$ is a positive integer in the range of 5 to 12 yielding $N^{\prime}$ s of 32 to 4096 in binary steps. Almost all commercial implementations of the FFT employ these transform sizes. 


\section{SYNCHRONOUS SAMPLING}

It has been discussed that the sampling process must provide a sample frame for an integer number of cycles of the incoming signal and an integer number of samples per cycle.

Acquisition of $2^{a}$ samples per cycle for $2^{b}$ cycles, where both $a$ and $b$ are positive integers, will meet this criterion and also ensure that the data record is some power of 2 in length. A suitable sample rate for a $60-\mathrm{Hz}$ current signal would, therefore, be $60 \times 2^{a}$, yielding sample frequencies of $120,240,480,960$, etc. There is also a need to ensure that sampling occurs at consistent positions in each successive cycle of the incoming signal. In order to do this, it becomes necessary to not only select a suitable sample frequency but also to precisely control that frequency. This is accomplished with a sample clock based on a phase-locked-loop (PLL) circuit that uses the fundamental signal frequency as an input reference. An appropriately configured PLL circuit can generate an exact number of sample-trigger pulses during each inputsignal cycle. When sampling is done in this way, the resulting FFT exhibits little or no energy spreading around the main spectral components (Fig. 4.1). Note that both Fig. 3.2 and 4.1 represent the same $60-\mathrm{Hz}$ signal sampled at $480 \mathrm{~Hz}$, but for Fig. 4.1, the sample clock was phase locked to the $60-\mathrm{Hz}$ signal. This technique, referred to as synchronous sampling, is the basis for a system recently developed for the monitoring of motor and compressor stages at USEC production facilities.

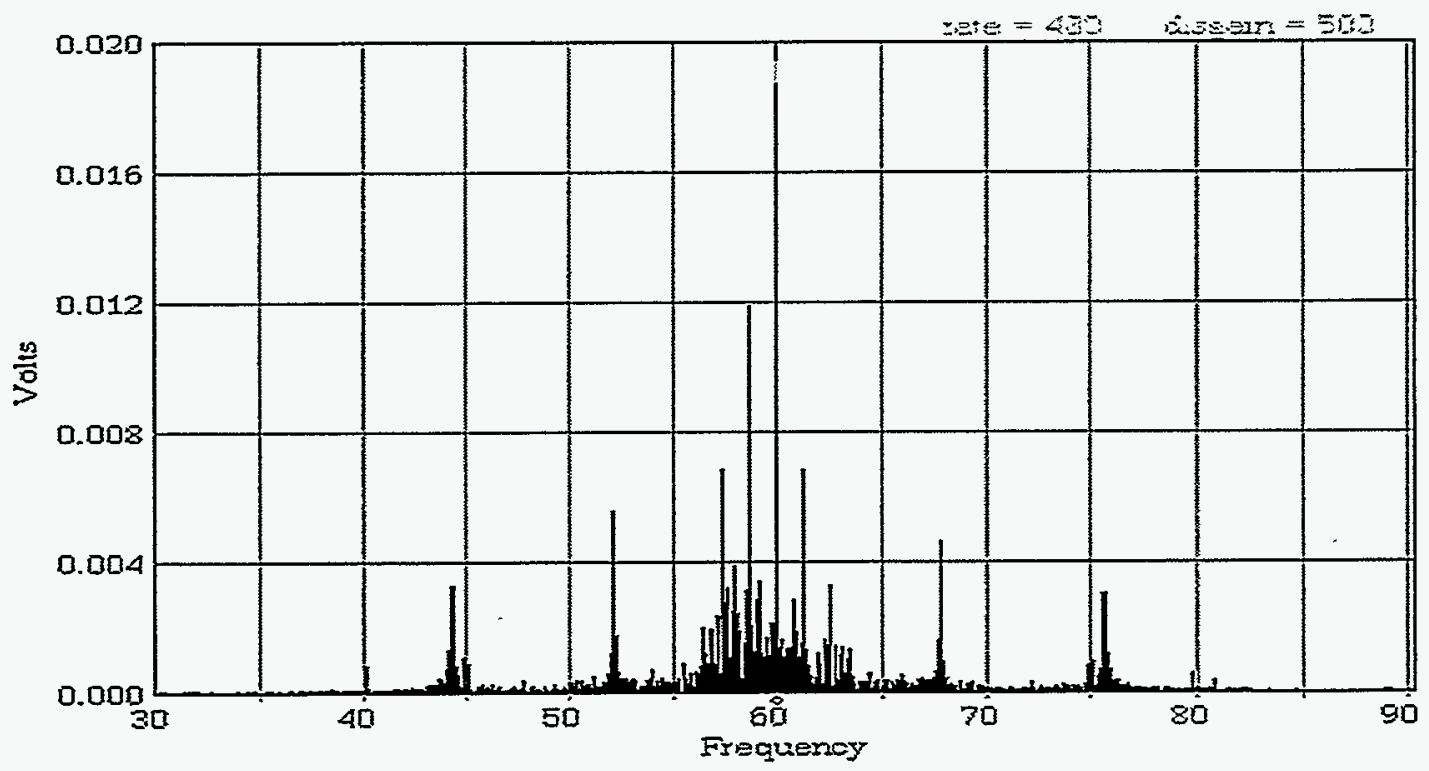

Fig. 4.1. Synchronous spectrum with display gain equal to 500 . 


\section{SYSTEM OVERVIEW}

During 1995, a monitoring system demonstrating the application of high-resolution synchronous sampling along with automated analysis was installed on 80 compressor stages in the X333 building at PORTS, and a similar system was installed in C333 at the Paducah Gaseous Diffusion Plant (PGDP). The X333 building houses 640 compressor stages driven by 3300 -hp motors, and there are 480 stages in C333. The stages are arranged in groups of eight, which are referred to as cells, and ten cells are then grouped together to form a unit. X333 and C333 contain eight and six units respectively, and the monitoring system for each building will dedicate a PC to the scanning and analysis of each 80-stage unit. Although a PC could easily handle more than 80 data channels, the unit-based configuration was selected to limit the average cycle time for the scanning and analysis of each unit to about $90 \mathrm{~s}$. Because of the emphasis on monitoring each unit independently, such systems have come to be called Unit Monitors.

A building system can employ up to eight unit processors (UPs), which acquire all data and perform all analyses. Each building system also incorporates an operator interface (OI), which receives and records data from the UPS and displays it for building operators. The OI computer, which is a PC located in the local control room, can receive and store data from up to eight UPs and can display those data in various operator selectable formats. To monitor the 640 stages in the X333 building would require a full system of eight UPs, but for now the installed demonstration systems are composed of a single UP and an OI (Fig. 5.1).

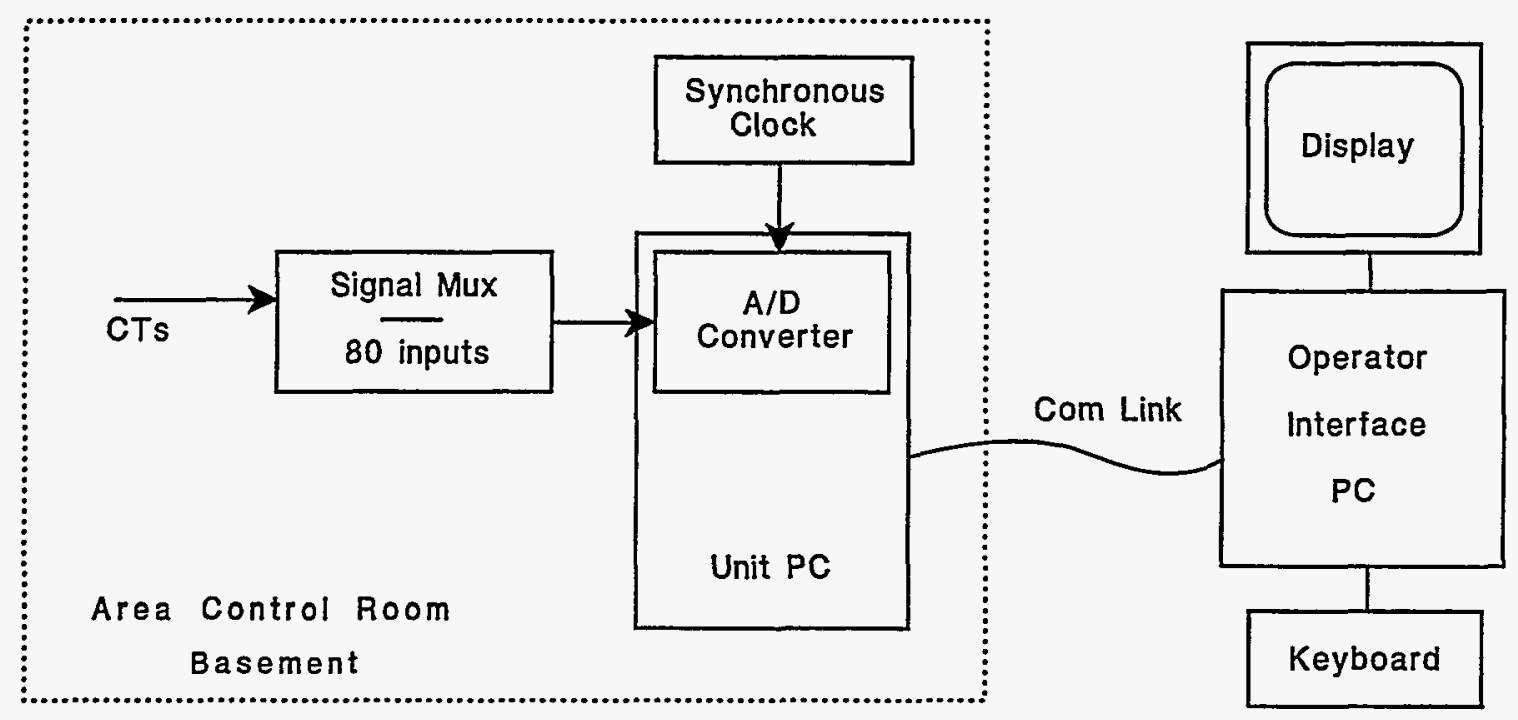

Fig. 5.1. Demonstration system configuration.

\subsection{EXPANDABLITY}

Demonstration systems are installed primarily to show how new monitoring concepts may be applied in a particular environment and often incorporate little consideration for the future use of the demonstration equipment. Expansion of such systems typically requires significant efforts 
in reengineering and reconfiguration of the hardware and software. The Unit Monitor demonstrations, however, were designed to be part of a larger system. The software and hardware for the systems at both PORTS and PGDP are configured so that expanded coverage can be accomplished by simply adding additional UPs. Communication lines from new UPs plug into serial-communication (COM) ports that are already part of the installed OI. When a new UP is added to the system, the OI software will automatically recognize it and make any data that it sends available for display.

\subsection{VIBRATION MONITORING}

In the near future, the Nuclear Regulatory Commission (NRC) may require dedicated vibration monitoring on all active process stages of the gaseous diffusion plants (GDPs). In expectation of this, PORTS Operations personnel are interested in the possibility of using CSA for vibration monitoring because a CSA system can be installed for less than half the cost of an accelerometer-based system. Although the frequency components found in motor-current signals often relate directly to vibration frequencies found with accelerometers on the same equipment, the use of CSA to generate alarms for high vibration is a relatively new concept that has not been thoroughly studied. As a result, the present ORNL work sponsored by the USEC is directed toward acquiring the necessary data for documentation to support this planned use. Lessons learned in this endeavor will, if needed, be incorporated into further improvement of the Unit Monitor software along with changes or upgrades that have been previously identified.

A vibration monitoring system employing a single compressor-mounted accelerometer for each stage already exists in some process buildings. This configuration provides good sensitivity to compressor vibration, but the sensitivity to drive-motor vibration is low and may not be acceptable in the future. CSA, on the other hand, is sensitive to torque variations occurring in or presented to the drive motor. Some of these torque variations result from the same equipment imbalances that cause vibration, so CSA can actually provide a composite vibration picture of the entire stage. It follows then that even if the NRC does not accept CSA as a complete replacement for accelerometer-based vibration monitoring, it may provide sufficient supplemental monitoring to avoid any future need for motor-mounted accelerometers. In a supplementary roll, CSA would not only provide needed motor protection but would also detect electrical problems and many load-related mechanical anomalies that normal vibration monitoring does not detect.

\subsection{SYSTEM EVALUATION}

The system in the PORTS X333 building was installed in May of 1995, and the C333 installation became operational in December of 1995. The systems are being used to test and improve system software and to gather operating data from the monitored stages. Data recorded by both systems are being used to document system performance, to define further improvements needed in the software, and to identify possible causes of stage failures in afterthe-fact examinations. At some time during the coming calendar year, the acquired data, operating experience, and system costs will have to be evaluated by a committee of engineers and managers from the two enrichment plants. That committee will initially have to assess the value of the installed CSA systems and decide whether or not to recommend the expanded use of such monitoring in the USEC facilities. 


\section{UNIT PROCESSORS}

Each UP is dedicated to the monitoring of an 80-stage unit, performing all of the data acquisition and signal analysis for that unit. With the exception of certain initialization data parameters, each UP is identical in both hardware and software to any other in the system. Although the data sampling of several UPs can be driven from a single synchronous-sample clock, the UPs are completely independent of one another, and their operations are asynchronous. System data transfers or communications occur only between the OI computer and the individual UPs. Since the origin of data received by the OI is determined solely by communications port identification on the OI computer, no special identity protocols are needed.

\subsection{HARDWARE}

The UP is built around a standard 33-MHz 486-type PC with an 80- to 100- MB hard disk and at least one serial-communications port designated COM1. UPs also contain a VGA-type video card although no video monitor or keyboard is required for normal operation. Special hardware includes a 16-bit A/D card (Analogic p/n LSDAS-16) connected to an external signal multiplexer (MUX) containing five 16-channel analog-input boards. The first of the input boards (Analogic p/n MUX-16TC) acts as the interface between the A/D card in the PC and other multiplexer cards. The remaining four boards (Analogic $\mathrm{p} / \mathrm{n} \mathrm{MUX}-16 \mathrm{TC} / \mathrm{EX}$ ) simply route signals onto the A/D-card signal bus. The A/D-card interface, set to a hexadecimal address of $0 \times 300$, controls all sampling and multiplexing functions. The first multiplexer board also receives a 3840-Hz sample-trigger signal from the external sample clock. Appendix A provides a listing of all system hardware along with any required jumper settings for the various circuit boards.

\subsubsection{Signal Acquisition}

The motor current signals are sensed directly from control room ammeter loops using clamp-on current transformers (CTs). The CTs (Amecon p/n 7733) produce an output voltage of $333 \mathrm{mV} \mathrm{rms}$ for a full-scale 5-A current in the meter loop. The signal from each CT is run via shielded, twisted-pair cable (Belden 8762) to a signal MUX located along with its UP computer in the control room basement. Appendix B provides a listing of MUX inputs for the installed demonstrations.

To reduce the cycle time required for analysis of the entire unit, signal data are acquired from eight motors at once using sample interleaving. Since only one A/D converter is used, acquisition of data requires channel switching between samples in order to achieve the necessary interleave. Sampling and channel switching are software controlled although sample triggering is accomplished with an external $3840-\mathrm{Hz}$ sample clock. Sample interleaving effectively divides the $3840-\mathrm{Hz}$ clock by eight, resulting in a per-stage sample rate of $480 \mathrm{~Hz}$. The sample trigger signal is presented continuously to the interface but is only used when data conversion is enabled by software. Each interleave-data scan involves 32,768 samples, or 4096 data points for each of the eight active channels. During acquisition, the samples are separated by channel into eight data arrays.

Before the interleave data from an eight-stage cell are acquired, another series of samples is acquired and used to determine the magnitude of the current. In this case, 128 samples, 
covering exactly two full cycles of the $60-\mathrm{Hz}$ power, are taken from one stage at a time at the full $3840-\mathrm{Hz}$ rate. These samples are auto-zeroed to remove any dc offset, and their absolute values are combined to derive the rms magnitude of the current. When the results of this operation have been recorded for each of the eight stages, the interleave data are acquired and analyzed. After the analysis of the entire cell, the results are coded into a status string, which is transmitted to the OI before sampling the next cell.

\subsubsection{Sample Clock}

The sample clock is a stand-alone, rack-mounted instrument that generates a $3840-\mathrm{Hz}$ square wave that is synchronized to the $60-\mathrm{Hz}$ frequency of its incoming $110-\mathrm{Vac}$ power. The circuit (Fig. 6.1) uses the phase detectors from two PLL integrated circuits to derive the control signal needed to phase lock one of the voltage-controlled oscillators to the incoming $60-\mathrm{Hz}$ power line. This configuration reduces control-voltage ripple and improves the stability of the clock frequency. Two individually buffered BNC-type output connections are provided, with each capable of driving the sample triggers for two or more UPs.

\subsection{SOFTWARE}

The UP software operates under DOS 3.2 or a later version and is compiled using Microsoft C, Version 6.0. At the time of this writing, there are $14 \mathrm{C}$-source files that are compiled in large-model mode and then linked to form the executable file, "unit.exe." The source files describe all system operations, including hardware interface control and interrupt processing. No software supplied with system hardware by the related vendors is needed in the compilation. The resulting "unit.exe" file is the same for the installations at both diffusion plants.

In normal operation, the UP does not require a keyboard or display terminal, so at powerup the "autoexec.bat" file assigns COM1 to act as the console device. In this way, the OI can be used to remotely access UP console functions. This then allows the OI to be used, when needed, as a remote terminal for the UP and also allows the OI software to automatically start the UP software. When the OI software is started, it sequentially asks each UP to execute a special batch file, "run-unit.bat." This simple file first assigns the console input/output stream for the UP back to the local terminal, so that DOS-generated prompts are not sent on COM1 to the OI. It then calls "unit.exe." When the executable file starts, it looks for a data initialization file, "init.dat" in the current directory. Values read from this file are used to initialize certain system parameters. The format for the data in the "init.dat" file can be determined from a listing of the "init par.c" file, which can be obtained from this author.

When the UP software starts, it immediately begins the sequential scanning and analysis of unit cells. Information resulting from each cell scan is subsequently sent to the OI. The scanning and analysis process continues indefinitely until either the UP power is removed or the UP receives a software abort command from the OI. When the software is aborted, the "rununit.bat" file reassigns the console stream back to the UP COM1.

\subsection{DATA ANALYSIS}

A cell analysis is begun by acquiring and processing the 128 samples from each of the eight stages at the full sample rate of $3840 \mathrm{~Hz}$. Using these data, the current amplitude for each 


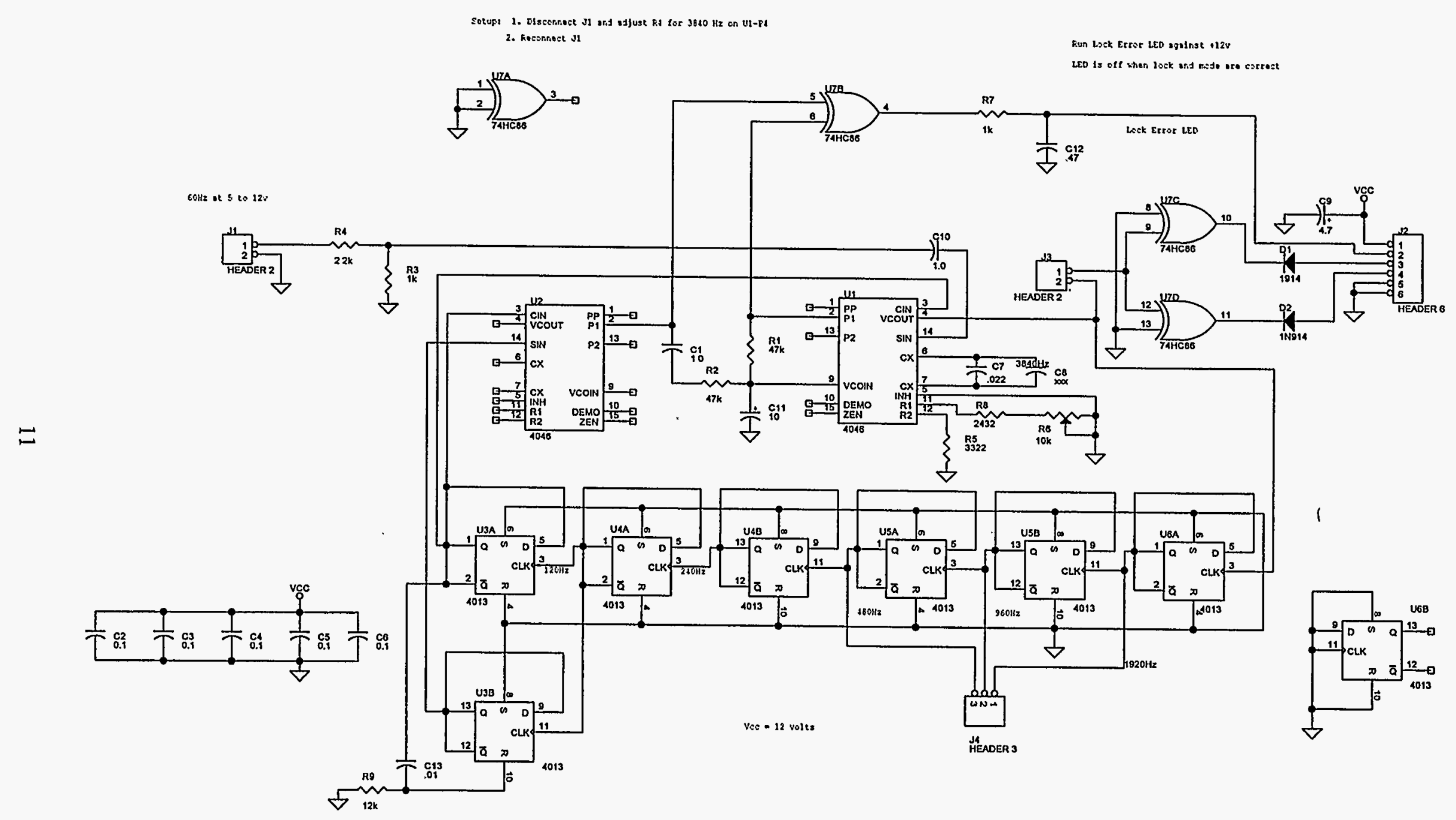

Fig. 6.1. Synchronous sample clock schematic. 
stage is found, and then the interleave data for the entire cell are acquired. All remaining analysis is performed one stage at a time by processing the 4096 data points from that stage. The first step in analyzing the interleave data is to make sure that the samples are synchronous. If the data are not synchronous, an error code is registered, and the analysis process for that stage is terminated until the next scan cycle. If the data are found to be synchronous, the data array is auto-zeroed in preparation for further processing. An initial examination of the raw sample data is made to determine if sufficient envelope perturbations exist to indicate compressor surging. If no surging is observed and if the current amplitude is above a predetermined level, an FFT is calculated. The FFT algorithm produces an array of 2048 complex vectors that represent the signal spectrum over a bandwidth of 0 to $240 \mathrm{~Hz}$. The remaining analysis involves the sequential sorting, examination, and combination of various FFT vectors to derive information relating to operating conditions.

The frequency and magnitude of the motor slip are first found and used to read motor speed to within about $1 \mathrm{rpm}$ and to check for electrical problems in the motor rotor. Figure 6.2 shows an FFT of a typical 000 -size motor operating at $3600 \mathrm{hp}$ with a $1.4-\mathrm{Hz}$ slip at $0.3 \%$ modulation. This slip yields an 1186-rpm running speed and is well below the $2 \%$ modulation that would be caused by a broken rotor bar in the motor. Next, the modulation index for the running speed component is found and compared to two thresholds, which are used for generating a vibration warning or an alarm for the stage. The way that vibration information is interpreted from the FFT may have to change as additional data, discussed in Sect. 5.2 of this report, are acquired and correlated. The final frequencies examined are between 8 and $9 \mathrm{~Hz}$. If a component is present in this range with a modulation index of about $0.1 \%$, it indicates the presence of a rotating-stall cell in the compressor. ${ }^{2}$

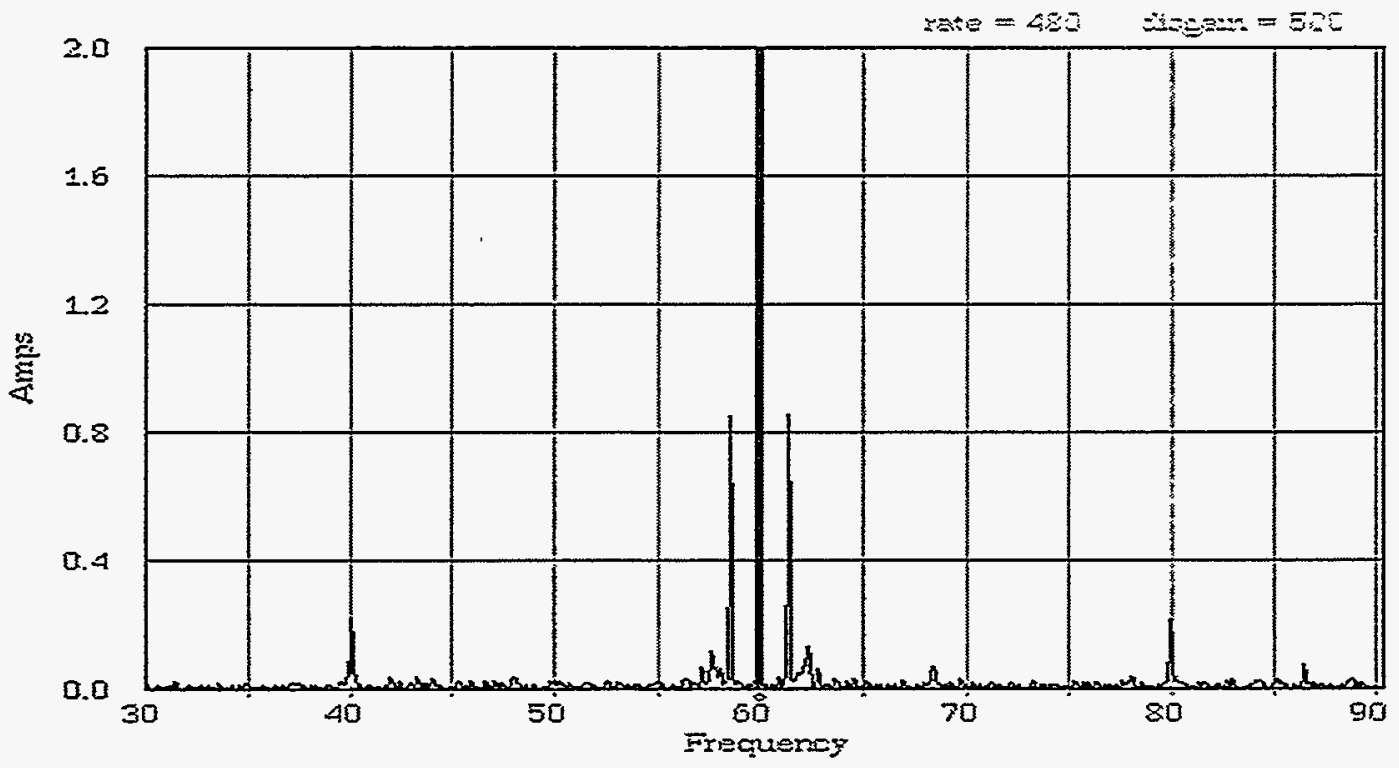

Fig. 6.2. Fast Fourier transform for a typical 000-size motor.

2 K. N. Castleberry and S. F. Smith, "A Dedicated Compressor Monitoring System Employing Current Signature Analysis," pp. 133-142 in Proceedings of the 47th Meeting of the Mechanical Failures Prevention Group, Virginia Beach, VA, April 13-15, 1993. 
The current version of the UP software implements routines designed to detect conditions that have a high occurrence rate or are of significant interest to plant operations personnel. Other equipment conditions, such as B-barrel surge, are less common, are of less concern, and are not as yet included in the software. Detection of such conditions may be added as the software matures.

\subsection{CODES AND FLAGS}

As the analysis of each stage progresses, condition flags and a stage-status code are used to record detected conditions and in some cases to control implementation of subsequent analysis. These flags and codes are part of the information sent to the system OI, where they are interpreted and recorded as part of the stage data. A listing of the status codes used in the UP software are listed in Table 6.1 along with the colors employed by the OI software to display them. Condition flags and error codes that are also associated with the analysis process are listed in Appendix C.

Table 6.1. Stage status codes

\begin{tabular}{ccc}
\hline Code & Status & Display Color \\
\hline 0 & No data available & Black \\
1 & Off-line & Gray \\
2 & $\begin{array}{c}\text { Stage running at less than } \\
500 \text { hp, no analysis } \\
\text { performed } \\
\text { On-line and normal } \\
\text { Hardware error } \\
4\end{array}$ & Cyan \\
5 & $\begin{array}{c}\text { Low alarm for surge, } \\
\text { secondary, abnormal } \\
\text { vibration, motor electrical, } \\
\text { etc. }\end{array}$ & Blue \\
& $\quad$ Yellow \\
& High alarm for vibration & Red \\
\hline
\end{tabular}

\subsection{STATUS AND EVENT FILES}

Each UP maintains data arrays, which contain all known status information for every stage in the associated unit. At the beginning of every hour, all of the status information stored for each stage is written into a single daily-status file, which accumulates the data for a 24-h period. The daily status filename is of the form, "1213.s21," which uses a four-digit-date code followed by " $s$ " for status and a two-digit file number. The last number is a counter that is used deleting files that are over 20 days old. These files are written into the "c:Istatus" directory on the UP hard-disk drive. The files are designed to be imported into a spreadsheet program like Microsoft 
Excel and contain only integer numbers. A complete file typically contains 1944 lines, which are 24 groups of 81 lines. Each group starts with a line containing the current hour number, which ranges from 0 to 24 . The 80 lines following the hour contain data for each stage in the unit. A stage-data line is composed of six integers separated by commas. The numbers represent, in order, the MUX channel number, stage status code, motor amps, run-speed modulation, motor-slip modulation, and condition flags. Additional information about these numbers is discussed in Appendix C.

Every stage also has its own set of counters in software for counting occurrences of warning and alarm conditions. Each time the analysis software finds a stage with a status code of four or higher, it records the occurrence by incrementing the related condition counter for that stage. These software stage-condition counters are reset to zero every day at 11:55 p.m. and allowed to increment, as needed, for $24 \mathrm{~h}$. At the end of each 24-h period, the nonzero counters are recorded in a daily event file. The daily events filename is of the form, "1213.e21," which uses a four-digit date code followed by " $\mathrm{e}$ " for event and a two-digit file number. These files are written into the "c:levents" directory on the UP hard-disk drive. These files, like the daily-status files, are designed to be imported into a spreadsheet program like Microsoft Excel and contain only integer numbers. Since only the counters for stages with detected events are recorded, these files vary in length from day to day. Each line of the file includes six integers beginning with the MUX channel number. The remaining five numbers are the recorded counts for surge, secondary, motor check, vibration low alarm, and vibration high alarm. Based on data from the X333 system, about 775 unit-analysis cycles are performed per day by a UP. It has therefore been shown that a condition detected in every scan during a 24 -h period would result in an event count of 775 for that condition and stage. 


\section{OPERATOR INTERFACE}

The OI is the control center for a unit monitor system. In that roll, the OI not only displays information in various screen formats about any monitored stage but also provides control functions, which allow the operator to select display modes and direct many of the functions of the UPs. The OI can receive status information from as many as eight unit processors, and it stores those data as required to make them available for display on request.

Operator input for controlling system functions is accomplished primarily through use of a touch-screen interface attached to the display terminal. The touch screen works in conjunction with a combination of soft-function buttons displayed at the bottom of most data screens (Fig. 7.1) and other screen-dependent touch boxes. Most functions can also be controlled using the PC keyboard, and some operations, such as access to terminal emulation for direct communications with a selected UP or exiting the OI software, require a password that must be input with the keyboard.

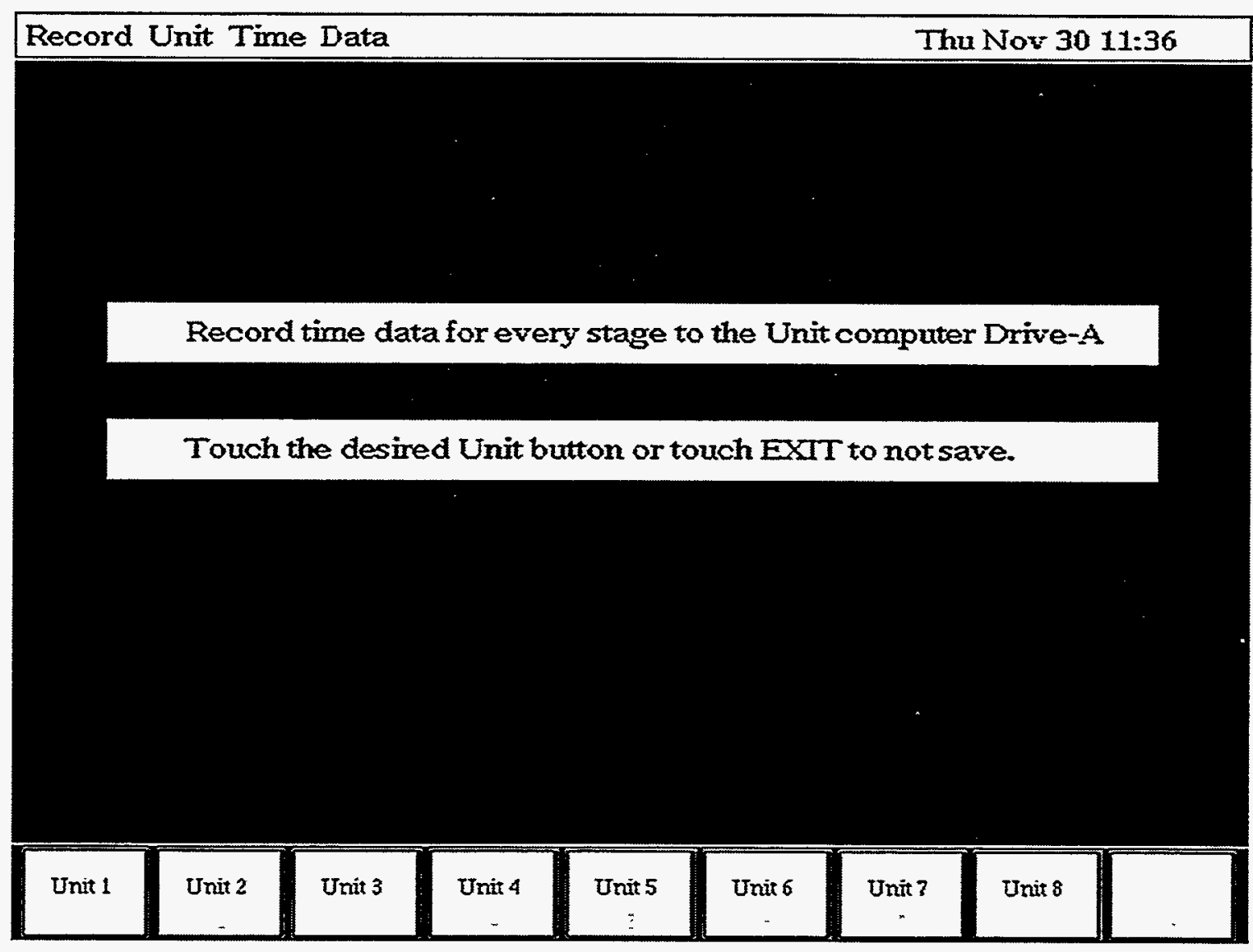

Fig. 7.1. Record Unit Time Data screen. 


\subsection{HARDWARE}

The OI is based on a standard 33-MHz, 486-type PC with a 14-in. color-graphics display fitted with an infrared touch-screen interface. The color display (part no. NEC-4FGE) was chosen to accept the touch-screen bezel and operates in standard VGA mode ( $640 \times 480$ pixels). The infrared touch-screen adapter (Carroll Touch part no. TS-8100-01) snaps directly onto the front of the monitor (Fig. 7.2) and interfaces to a hardware-based controller (Carroll Touch part no. TS-8100-HBC), which is installed in the operator interface PC. The interface is set to a hexadecimal address of $0 \times 310$ and uses the number-seven interrupt-request line.

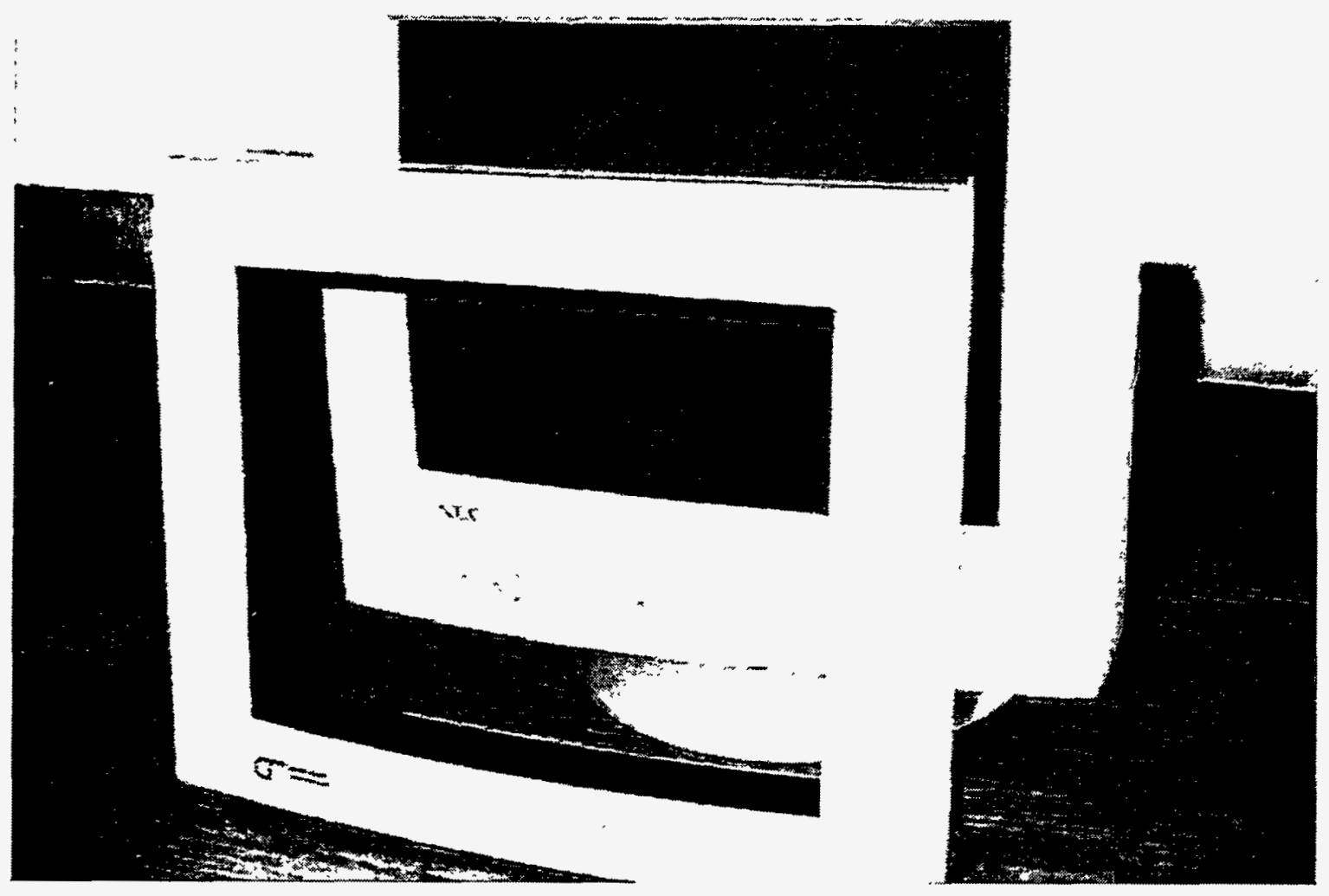

Fig. 7.2. Touch-screen interface.

An eight-port COM interface (Industrial Computer Source part no. FastCom8) allows data, status, and command transfers between the OI and the UPs. The interface is set to a hexadecimal address of $0 \times 280$ and uses the number-five PC-interrupt-request line. The COM line parameters are 9600 baud, eight data bits, one stop bit, and no parity. All communications are interrupt driven, so the COM cables employ no handshaking.

\subsection{SOFTWARE}

The OI software, like the UP software, operates under DOS 3.2 or a later version and is compiled using Microsoft C, Version 6.0. At the time of this writing, there are $29 \mathrm{C}$-source files 
that are compiled in large-model mode and then linked to form the executable file, "x333.exe" or "c333.exe." No software supplied with system hardware by the related vendors is needed in the compilation or in running the programs.

\subsection{DISPLAY MODES AND CONTROL FUNCTIONS}

The OI software provides a number of display formats for viewing system data. Soft function buttons, which allow system operators to change display modes or control system operations related to the current display, are provided at the bottom of each screen. Since there are so many data displays available, access to certain data displays can only be accomplished by going through other displays. The software hierarchy chart (Fig. 7.3) illustrates the path for accessing the various display modes.

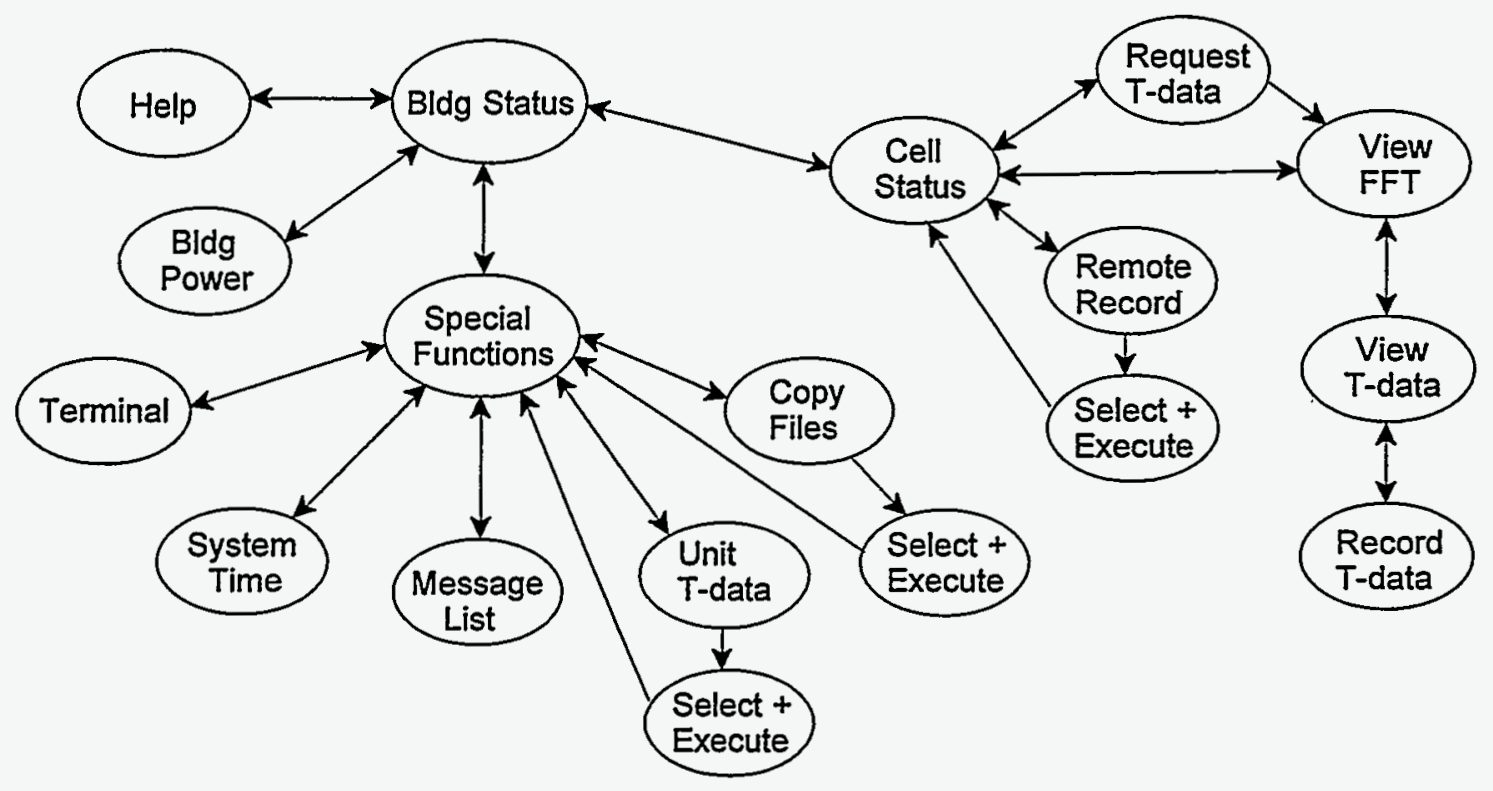

Fig. 7.3. Access to OI display modes.

\subsubsection{Building Status}

When the OI software is loaded, the Building Status screen (Fig. 7.4) appears first. This screen displays status indicators for cells in up to eight units. The individual cell indicators display composite information for that cell. Color is used to show cell status, where the color of the cell indicator generally indicates the highest status code of any stage in that cell. A variance from this occurs when a stage hardware error, code level four, is detected in a cell with a status of three or less. In this instance, a small blue square will appear inside the Cell Indicator area. Each Cell Indicator is also a touch pad that accesses a cell data screen that provides stage-bystage status information and access to other cell-related functions. At the bottom of the Building Status screen, there are soft function buttons (Table 7.1), which access other data screens or control functions. 


\subsubsection{Help}

Touching the Help button at the bottom of the Building Status screen causes the display to switch to Help mode. This mode simply provides for the display of a number of selectable text files that explain many aspects of system operation. These files can be viewed at any time without interfering with other system functions.

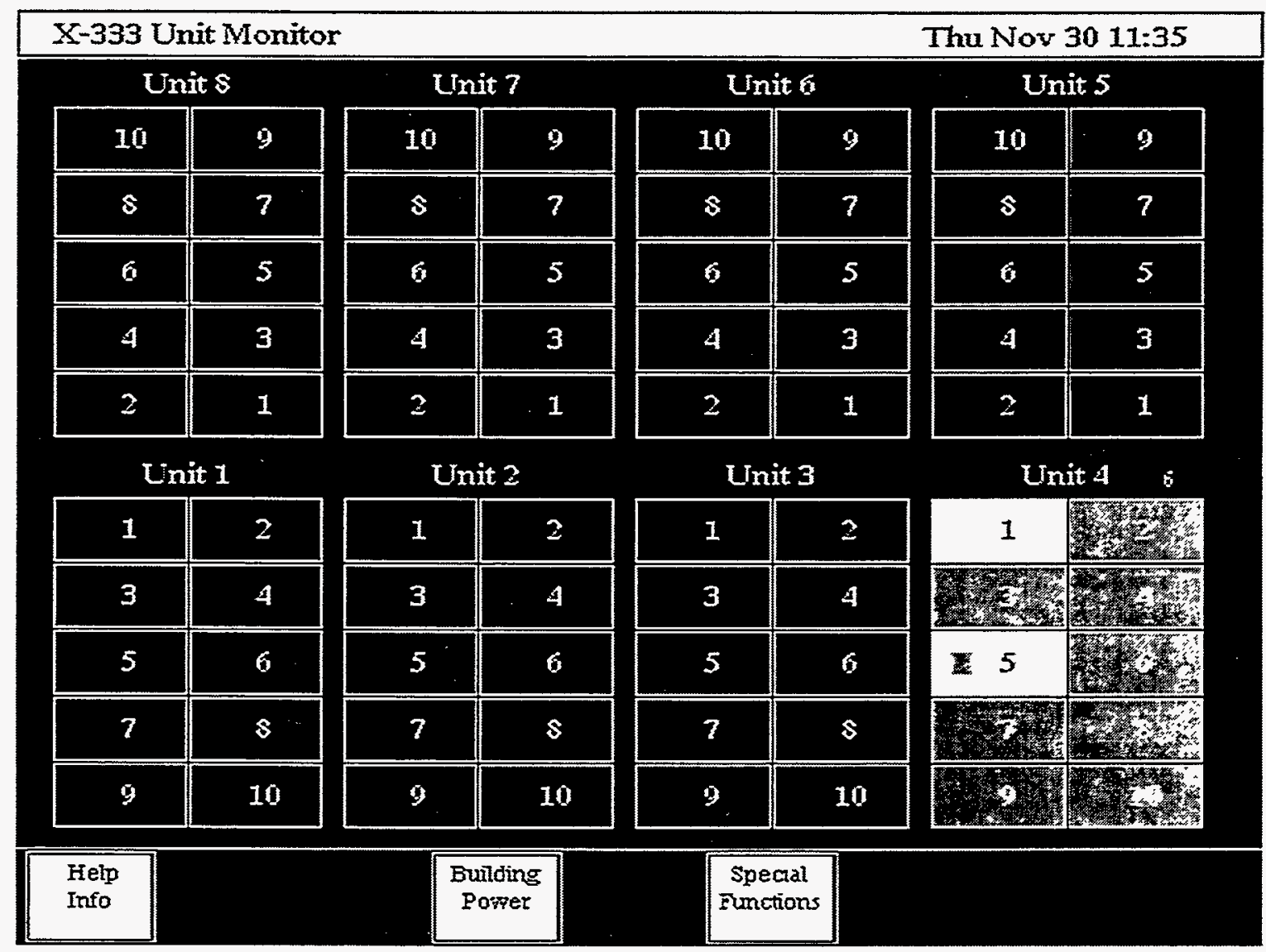

Fig. 7.4. Building Status screen.

Table 7.1. Building Status screen function buttons

\begin{tabular}{ll}
\hline \multicolumn{1}{c}{ Label } & \multicolumn{1}{c}{ Function } \\
\hline Help Info & Accesses on-line system help files. \\
Building & $\begin{array}{l}\text { Shows a plot of the horsepower distribution } \\
\text { in the building. }\end{array}$ \\
Power & $\begin{array}{l}\text { Accesses several system control and data } \\
\text { Functions }\end{array}$ \\
\hline
\end{tabular}




\subsubsection{Cell Data Screen}

The Cell Data screen (Fig. 7.5) provides information for each individual stage in the cell. The stage indicator color shows the overall stage status, and the stage information box below the color indicator lists several stage parameters. If the cell status is BLUE, YELLOW, or RED, the information box will also provide a short message describing the abnormal condition. For example, if the status is BLUE, a message in the box might read, "A/D Over Range - Input Open Circuit." Such a message should be reported to the area supervisor so that corrective action can be taken. A YELLOW status is a stage problem warning, which includes both compressor aerodynamic phenomena and abnormal vibration. Certain conditions may require control valve manipulation to correct. A RED status is reserved for suspected high vibration and should prompt an immediate inspection of the stage. As with most other screens, a group of function buttons (Table 7.2) are displayed at the bottom of the Cell Data screen.

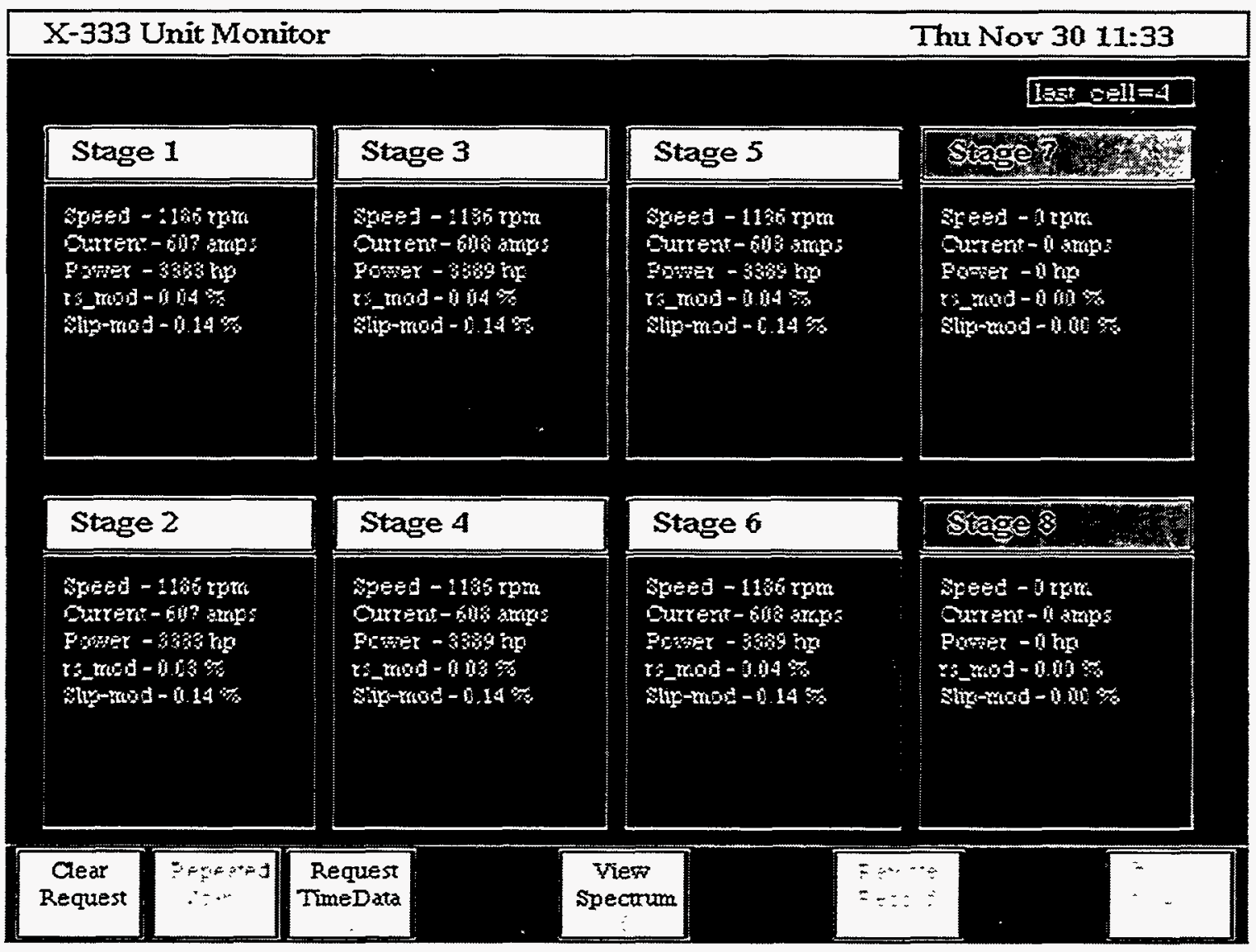

Fig. 7.5. Cell Data screen.

\subsubsection{FFT Spectrum Screen}

When the OI receives time-data samples from a UP, the data are stored in an array that the OI software associates with that UP, and an FFT is calculated from those data and displayed automatically. There is only one FFT array maintained by the OI software, but it keeps a separate time-data array for each UP. Whenever an operator views cell data from a different unit and then accesses the FFT screen using the View Spectrum button on the Cell Data screen, the 
Table 7.2. Cell Data screen function buttons

\begin{tabular}{|c|c|}
\hline Label & Function \\
\hline Clear & In case of a communication error, this tells the \\
\hline Request & OI to stop looking for time data from a UP. \\
\hline $\begin{array}{l}\text { Repeated } \\
\text { Scan }\end{array}$ & $\begin{array}{l}\text { Stops sequential cell scanning and repeatedly } \\
\text { takes data from the displayed cell. }\end{array}$ \\
\hline $\begin{array}{l}\text { Request } \\
\text { Time Data }\end{array}$ & $\begin{array}{l}\text { Tells a UP to acquire time data from a stage and } \\
\text { send them to the OI for viewing and analysis. }\end{array}$ \\
\hline $\begin{array}{l}\text { View } \\
\text { Spectrum }\end{array}$ & $\begin{array}{l}\text { Will switch the display to view the FFT for the } \\
\text { last time data sent from the UP. }\end{array}$ \\
\hline $\begin{array}{l}\text { Remote } \\
\text { Record }\end{array}$ & $\begin{array}{l}\text { Tells the UP to record the sample data for a stage } \\
\text { or cell to disk files on its drive-A. }\end{array}$ \\
\hline $\begin{array}{l}\text { Back to } \\
\text { BldgStat }\end{array}$ & Returns to the Building Status screen. \\
\hline
\end{tabular}

FFT for the data stored from that UP is recalculated automatically so it can be displayed. If a blank FFT plot is shown, it means that no time data have ever been requested and received from the selected UP.

The FFT screen (Fig. 7.6) displays a plot of the calculated FFT from the time data received from the UP associated with the Cell Data screen that accessed the FFT screen. The FFT contains 2048 points, but the display can only show 512 points at once. Provision is therefore made for panning the plot frequency so that all 2048 points can be viewed. The function buttons (Table 7.3) at the bottom of the screen provide control functions for modifying several display parameters for the FFT data. Two of the buttons are used to toggle between display modes, and their labels change to indicate the next change direction. Another button accesses a plot of the time data array.

\subsubsection{Time Data Screen}

A Time Data screen (Fig. 7.7) can be accessed only from the related FFT Spectrum screen. It provides an oscilloscope-type plot of the recorded time data. The plot area can show only 512 data points at a time, so function buttons are provided to pan over the entire 4096 data points. Table 7.4 provides an explanation of the screen function buttons.

\subsubsection{Power Distribution Screen}

X333 building personnel do not have a display of the building pressure taper like the one in C333, so the Power Distribution screen (Fig. . 7.8) shows the next best thing, a plot of the cell power distribution in the building. The motor current for each stage is read during each data acquisition scan and multiplied with the assumed motor voltage and a unit power factor to get the stage horsepower. The power factor for each monitored unit is input to the OI software in its 
"init.dat file." The cell horsepower is just the total of its eight stages. There is only one function button for this screen; it returns the display mode back to the Building Status screen.

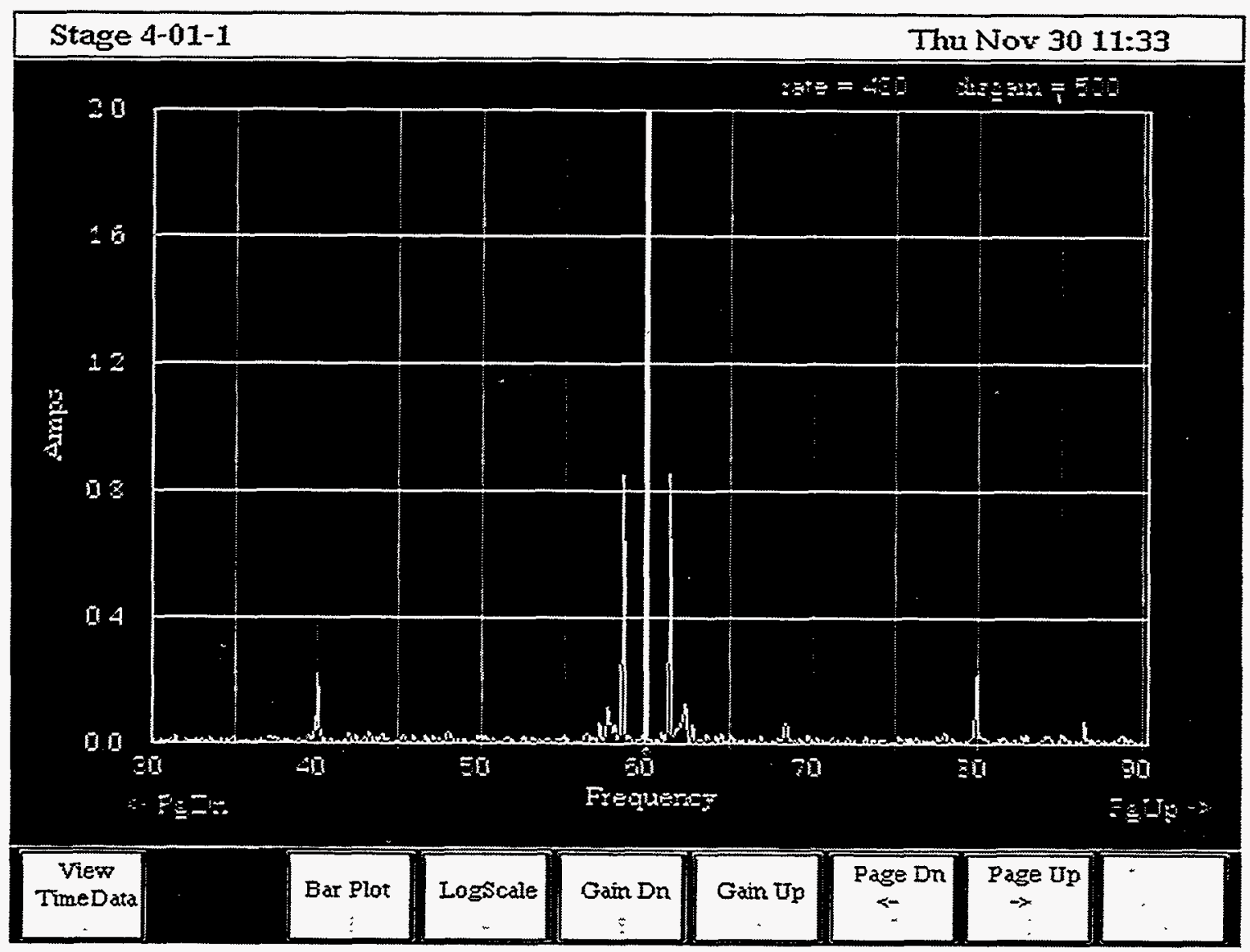

Fig. 7.6. FFT Spectrum screen.

\subsubsection{Special Functions}

The Special Functions screen (Fig. 7.9) provides access to miscellaneous system control and data request functions. At the time of this writing, two of the displayed function buttons, Message List and the System Time, have not yet been implemented in the OI software, but their intention will be explained.

The Terminal button accesses a terminal emulation routine that allows the OI display and keyboard to be used as a remote terminal for any active UP. To prevent possible interference with system operation by any other than engineering personnel, a password must be entered before this routine will actually engage. Once the terminal mode is active, keyboard function keys control terminal-mode functions. Function-key F1 displays a listing and explanation of the active function keys.

The System Time button will allow the OI real-time clock to be set, as needed, without having to exit the OI software. When this function is used, the entered time is also used to set the clock in each active UP.

The Message List button will display a list of the 20 most recent system error messages or operator prompts along with each message origin. 
The Unit T-data button displays a screen that allows an operator to cause any UP to save all of the time data for every stage during the very next scan series. The time data are saved in individual stage files on a floppy disk, which must already be loaded in the UP drive-A.

The Copy Files button displays a screen that allows an operator to tell a UP to move all of its archived status and event files to a floppy disk, which must already be loaded in the drive-A of the selected UP.

Table 7.3. FFT screen function buttons

\begin{tabular}{ll}
\hline \multicolumn{1}{c}{ Label } & \multicolumn{1}{c}{ Function } \\
\hline View Time Data & Shows an oscilloscope-type plot of the stored time data. \\
Bar Plot & Switches to bar-plot mode when in line-plot mode. \\
Line Plot & Switches to line-plot mode when in bar-plot mode. \\
LogScale & Switches to logarithmic vertical scale. \\
LinScale & Switches to a linear vertical scale. \\
Gain Dn & Decreases the vertical scale gain when in linear mode. \\
Gain Up & Increases the vertical scale gain when in linear mode. \\
Page Dn & Pans the FFT plot down in frequency. \\
Page Up & Pans the FFT plot up in frequency. \\
Back to Cell Scr & Exits to the Cell Data screen.
\end{tabular}




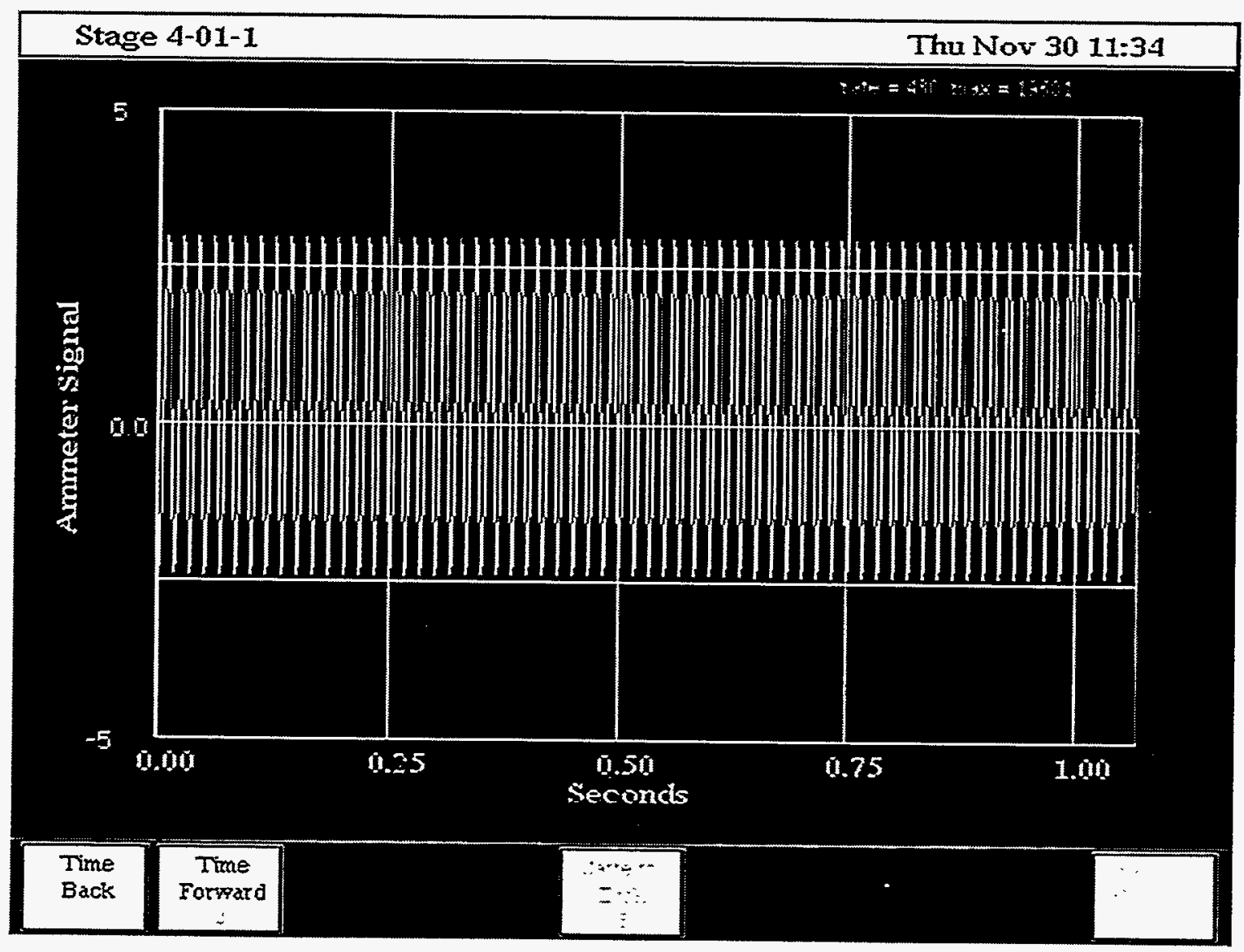

Fig. 7.7. Time Data screen.

Table 7.4. Time Data screen function buttons

\begin{tabular}{ll}
\hline \multicolumn{1}{c}{ Label } & \multicolumn{1}{c}{ Function } \\
\hline Time Back & $\begin{array}{l}\text { Pans back toward time zero in the data array } \\
\text { in 1-s steps. }\end{array}$ \\
$\begin{array}{ll}\text { Time } & \begin{array}{l}\text { Pans the display forward in time through the } \\
\text { data array in 1-s steps. }\end{array} \\
\text { Sorward } & \begin{array}{l}\text { Allows the viewed time data to be stored to a } \\
\text { file on the OI drive-A. }\end{array} \\
\text { Back to } & \text { Exits back to the FFT Spectrum screen. } \\
\text { FFT Scrn } & \end{array}$ \\
\hline
\end{tabular}




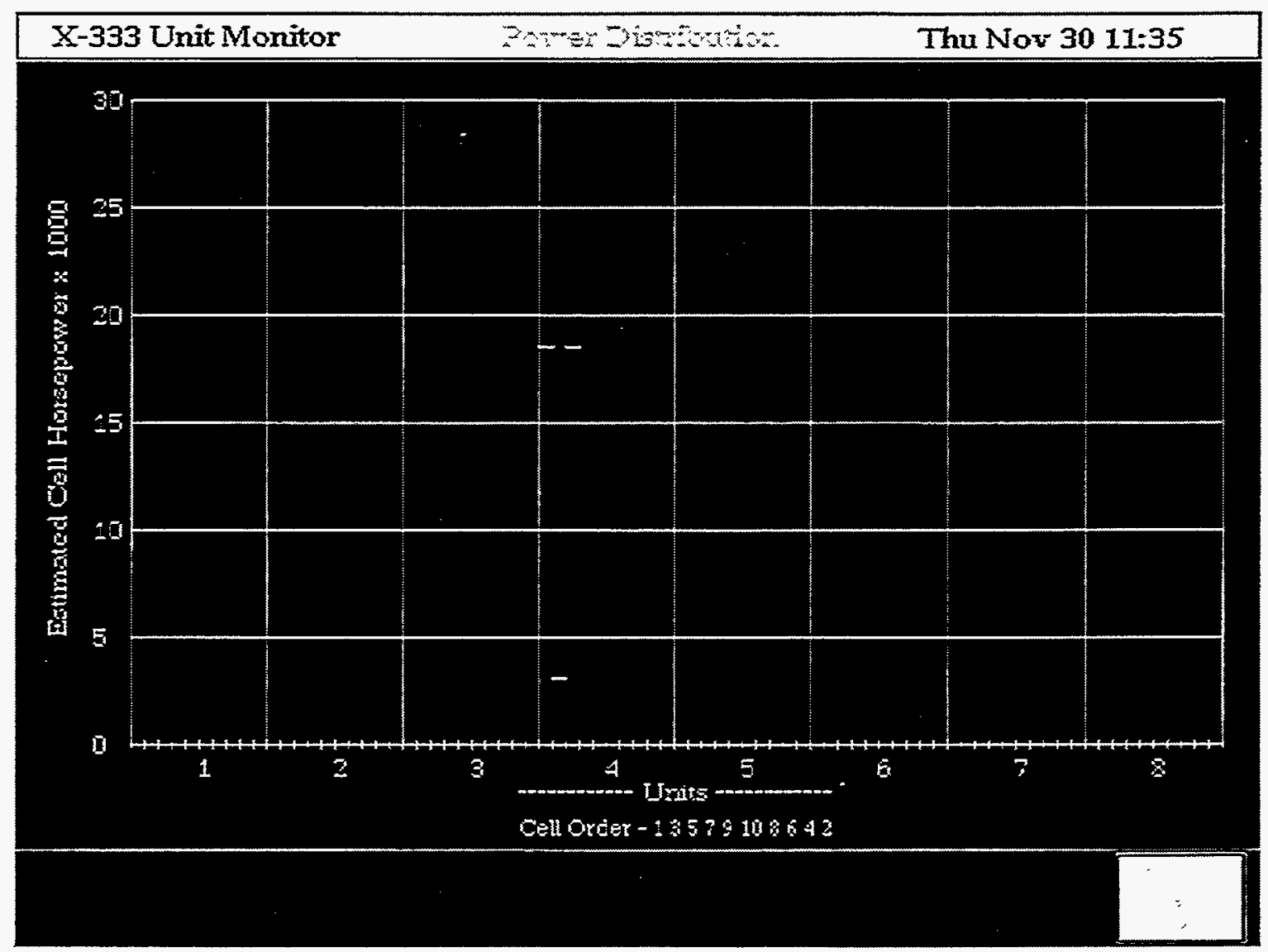

Fig. 7.8. Power Distribution screen. 


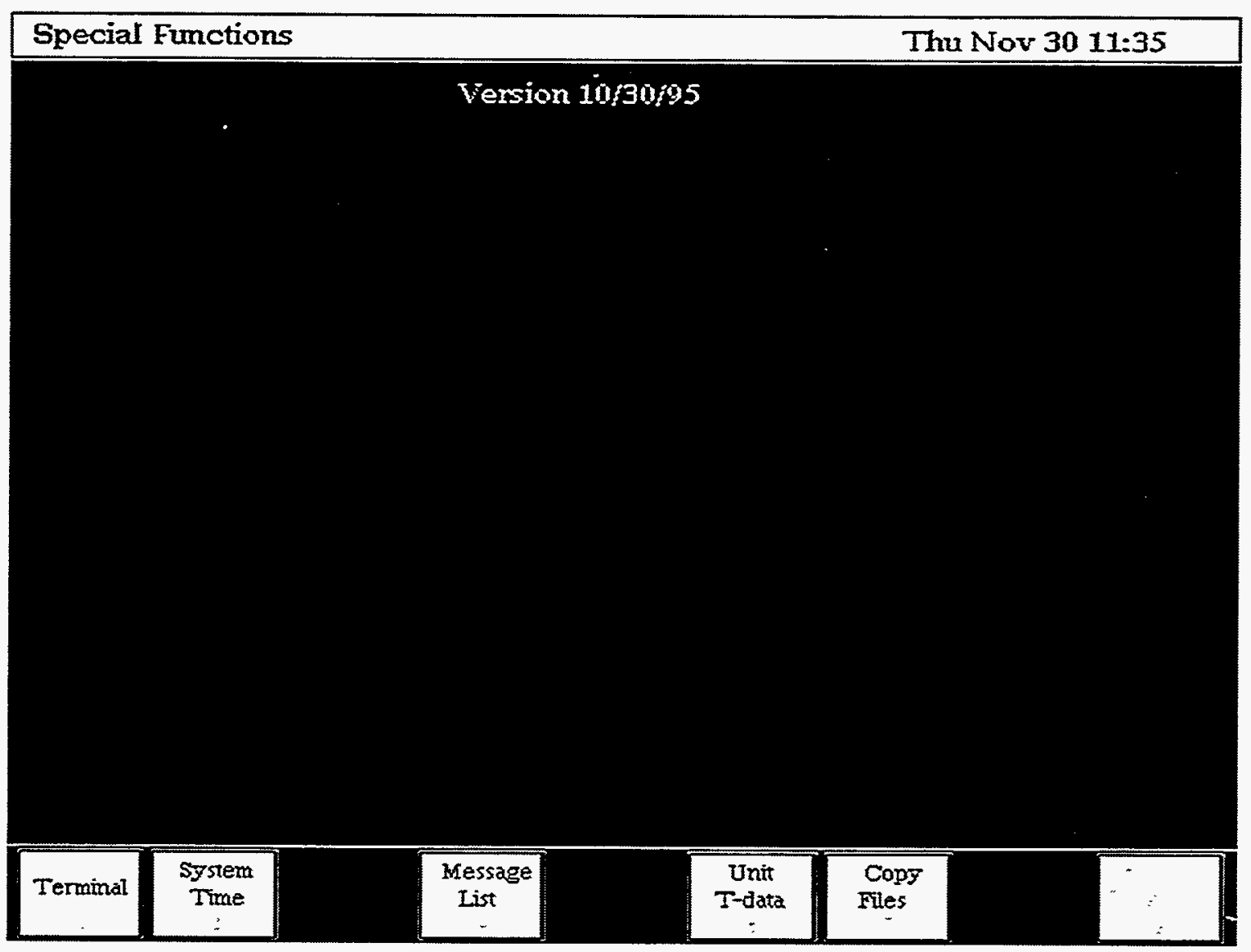

Fig. 7.9. Special Functions screen. 


\section{FINAL COMMENTS}

A significant advantage of the CSA systems being demonstrated is that they perform very specialized analysis using special software to control generic hardware. This means that practically any future developments in CSA processing can be added to a previously installed system simply by loading new software. As currently configured, Unit Monitor systems are installed at a low per-stage cost because they use common PCs and inexpensive sensors, all installation occurs in cascade area control rooms, and stage equipment does not have to be shut down during installation of the monitoring system. The current estimate for installation on 000 -size GDP stages is about $\$ 20 \mathrm{~K}$ per unit for material and installation labor excluding site Engineering costs. 
Appendix A

SYSTEM HARDWARE 
. 


\section{OPERATOR INTERFACE}

The hardware listing in Table A.1 describes the equipment that is installed as the OI in X333 at the Portsmouth plant. Substitutions were made by PGDP personnel in procuring some items, like the PCs, for the C333 demonstration. Many of the part numbers listed were procured from Industrial Computer Source (ICS).

Table A.1. OI hardware

\begin{tabular}{clc}
\hline Qty & \multicolumn{1}{c}{ Item } & Cost/each (\$) \\
\hline 1 & PC-386, rack mount version, ICS RMSYS4A & 1995 \\
1 & PC keyboard, rack mount version, ICS 6531-KBD/A & 325 \\
1 & 15-in. monitor, NEC model 4FGE & 500 \\
1 & Touch Screen, ICS 8100TS-3 & 449 \\
1 & Touch Screen controller, ICS 8200TSC-2 & 115 \\
1 & 8 port, RS-232 COM board, ICS FastCom8 & 599 \\
1 & 19-in. rack for PC and monitor & \\
\hline
\end{tabular}

The Touch Screen Controller is configured for an address of $0 \times 310$ and interrupt request seven. The FastCom 8 board uses the default address of $0 \times 280(\mathrm{SW} 1=10101111)$ and interrupt request five $(\mathrm{SW} 2=10001000)$.

\section{UNIT PROCESSOR}

Hardware used in the UP installed in the X333 demonstration is listed in Table A.2.

Table A.2. UP hardware

\begin{tabular}{clc}
\hline Qty & \multicolumn{1}{c}{ Item } & Cost/each (\$) \\
\hline 1 & PC-386, rack mount version, ICS RMSYS4A & 1995 \\
1 & PC keyboard, rack mount version, ICS 6531-KBD/A & 325 \\
1 & Monitor rack mount kit, ICS 6531-UM & 329 \\
1 & 16-bit A/D card for a PC, Analogic LSDAS-16 & 1395 \\
1 & 16-channel MUX card, Analogic MUX-16TC & 399 \\
4 & 16-channel MUX expander card, Analogic MUX- & 325 \\
& 16TC/EX & 20 \\
4 & Cable, Analogic EXPCAB-16 & 110 \\
1 & Cable, Analogic ACAB-22/LN & 110 \\
1 & Cable, Analogic DCAB-22 & \\
1 & 19 in rack, 6 ft tall & \\
& Custom mounting hardware for MUX boards \\
\hline
\end{tabular}

All of the jumpers on the Analogic LSDAS-16 board are left at their default settings. The ACAB-22 and the DCAB-22 cables connect the LSDAS-16 card in the PC to the MUX-16TC card in the MUX rack. 
The MUX16-TC board is jumpered for AVD channel 1. No other board jumpers are installed. The four MUX16-TC/EX boards are jumpered for channels 2 through 5 respectively, and no other jumpers are needed on these boards either.

The sample clock signal is connected via coaxial cable to the EPACE input and GND on the MUX16-TC board.

\section{Multiplexer Card Mounting Rack}

The multiplexer cards are mounted in a fabricated rack (Fig. A.1) using hardware listed in Table A.3. The configuration holds the boards at an angle and allows access to the input wiring terminals without having to remove the boards from the rack. The manufacturer of the components in Table A.3 is Vector Electronics Company.

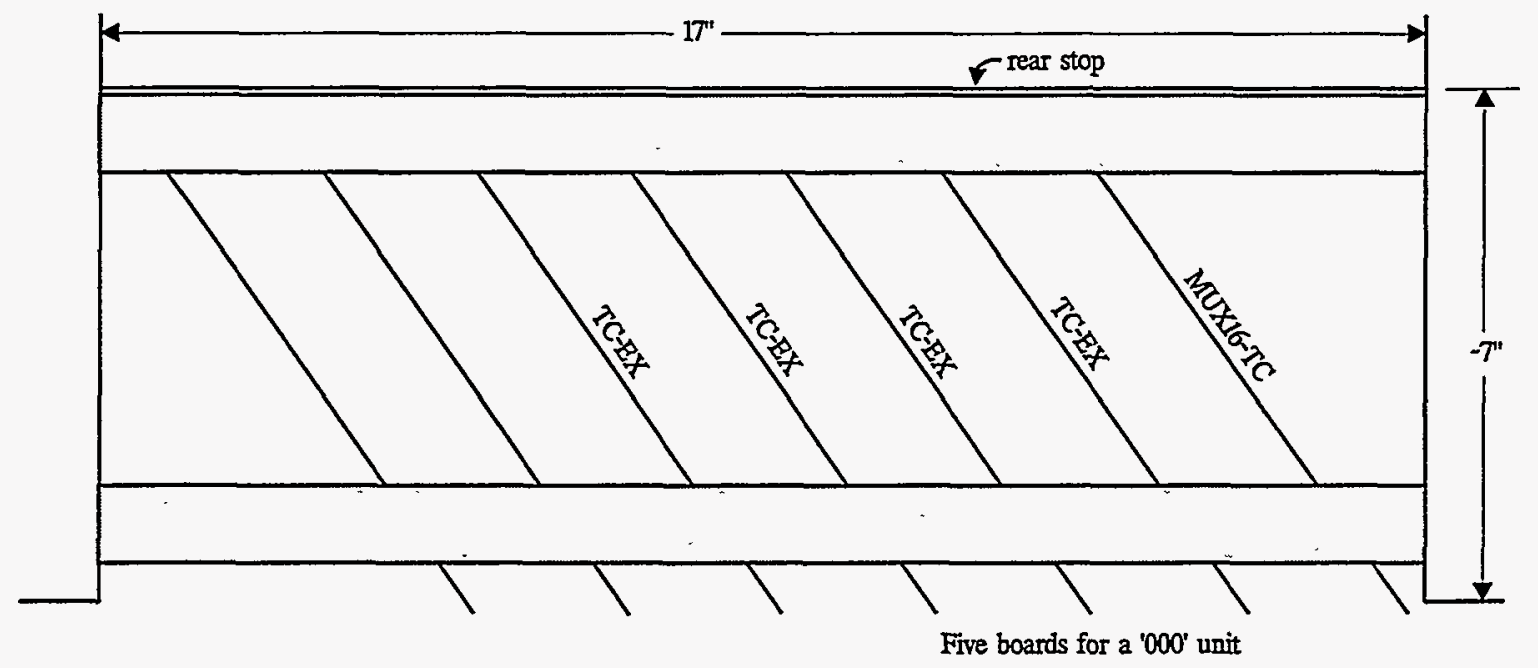

Fig. A.1. Multiplexer board mounting configuration (top view).

Table A.3. MUX rack components

\begin{tabular}{ccll}
\hline Item & $\begin{array}{c}\text { Number } \\
\text { required }\end{array}$ & \multicolumn{1}{c}{ Description } & \multicolumn{1}{c}{ Part No. } \\
\hline 1 & 2 & Sidewall & SW104P156/90 \\
2 & 4 & T-Strut, 16.85 in. & TS169 \\
3 & 8 & T-Strut bracket & BR16A \\
4 & 2 & Card Guide 12 each/pack & CG2-80P \\
\hline
\end{tabular}




\section{COMMUNICATION CABLING}

As previously described in Sect. 7.1, system COM lines are interrupt driven and do not require any handshake signals to function. The interconnecting cables between the OI and each UP are therefore wired to transfer only data signals (Fig. A.2).

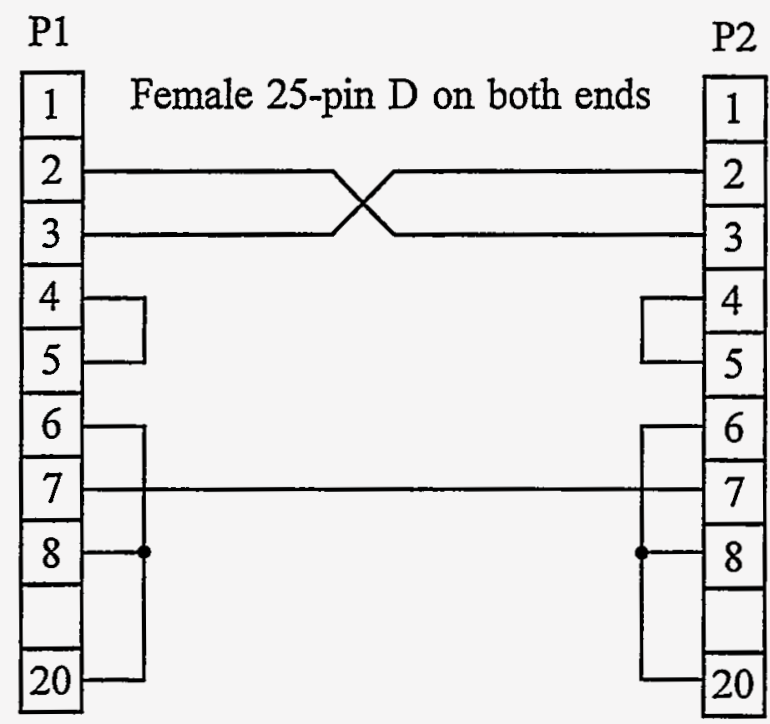

Fig. A.2. COM cable wiring 


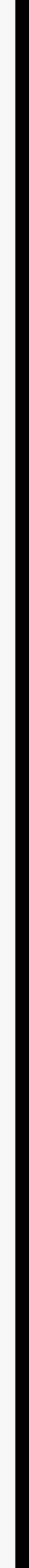


Appendix B

MULTIPLEXER INPUT WIRING 


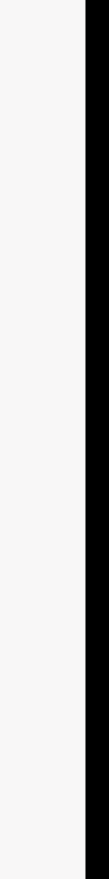


Proper cable configuration for CT signals to the MUX inputs is shown in Fig. B.1. This method is used for all CT signals. The stage vs MUX channel wiring (Table B.1) is the same for all 000-size units. Table B.1 also indicates the preferred physical arrangement for the MUX boards.

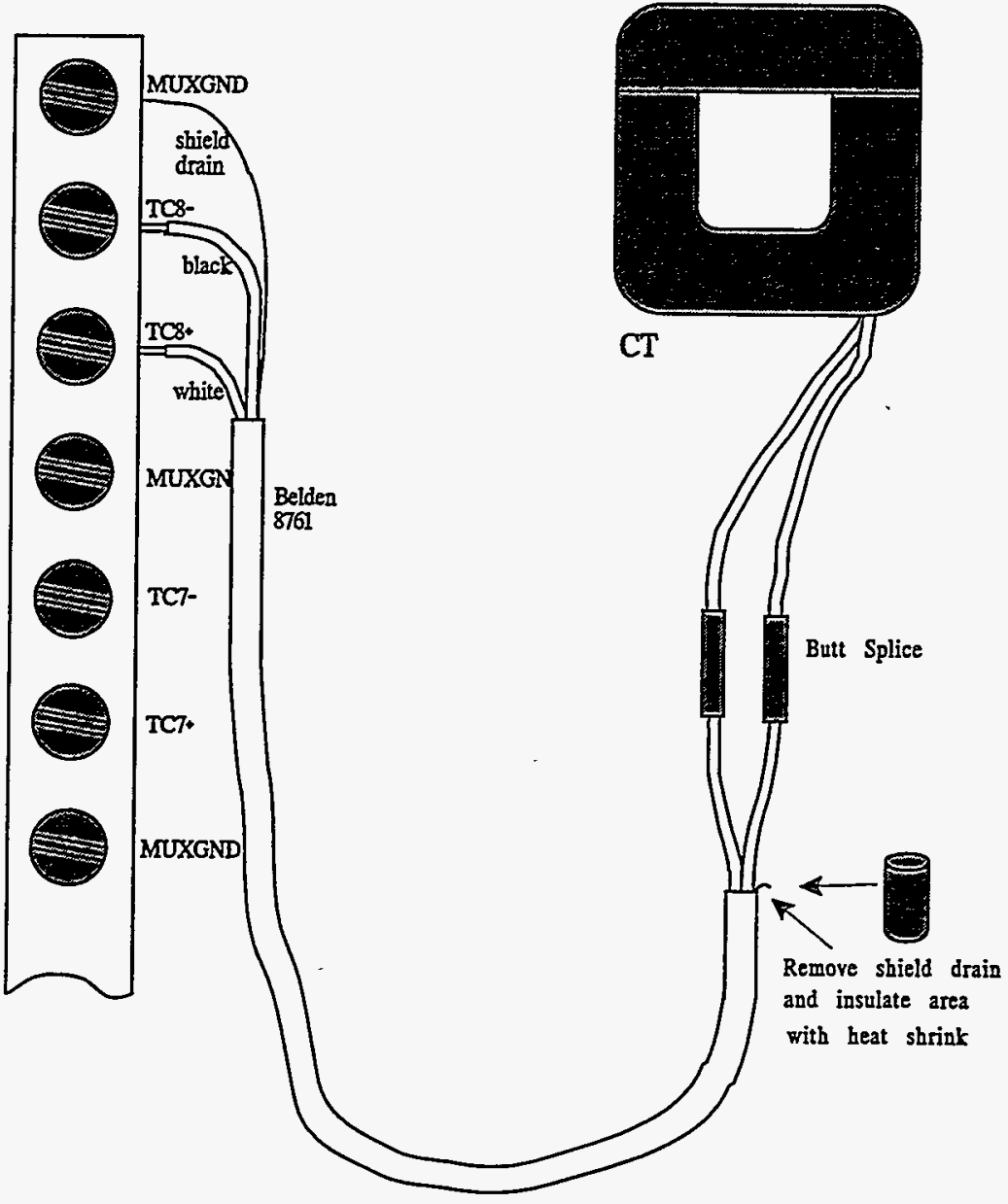

Fig. B.1. Typical cabling configuration ( CT to multiplexer). 
Table B.1. Stage vs MUX input

\begin{tabular}{|c|c|c|c|c|c|c|c|c|c|}
\hline \multicolumn{2}{|c|}{ Board 5} & \multicolumn{2}{|c|}{ Board 4} & \multicolumn{2}{|c|}{ Board 3} & \multicolumn{2}{|c|}{ Board 2} & \multicolumn{2}{|c|}{ Board 1} \\
\hline Inputs & Stage & Inputs & Stage & Inputs & Stage & Inputs & Stage & Inputs & Stage \\
\hline 1 & $9-1$ & 1 & $7-1$ & 1 & $5-1$ & 1 & $3-1$ & 1 & $1-1$ \\
\hline 2 & $9-2$ & 2 & $7-2$ & 2 & $5-2$ & 2 & $3-2$ & 2 & $1-2$ \\
\hline 3 & $9-3$ & 3 & $7-3$ & 3 & $5-3$ & 3 & $3-3$ & 3 & $1-3$ \\
\hline 4 & $9-4$ & 4 & $7-4$ & 4 & $5-4$ & 4 & $3-4$ & 4 & $1-4$ \\
\hline 5 & $9-5$ & 5 & 7.5 & 5 & $5-5$ & 5 & $3-5$ & 5 & $1-5$ \\
\hline 6 & $9-6$ & 6 & $7-6$ & 6 & $5-6$ & 6 & $3-6$ & 6 & $1-6$ \\
\hline 7 & $9-7$ & 7 & $7-7$ & 7 & $5-7$ & 7 & $3-7$ & 7 & $1-7$ \\
\hline 8 & $9-8$ & 8 & $7-8$ & 8 & $5-8$ & 8 & $3-8$ & 8 & $1-8$ \\
\hline 9 & $10-1$ & 9 & $8-1$ & 9 & $6-1$ & 9 & $4-1$ & 9 & $2-1$ \\
\hline 10 & $10-2$ & 10 & $8-2$ & 10 & $6-2$ & 10 & $4-2$ & 10 & $2-2$ \\
\hline 11 & $10-3$ & 11 & $8-3$ & 11 & $6-3$ & 11 & $4-3$ & 11 & $2-3$ \\
\hline 12 & $10-4$ & 12 & $8-4$ & 12 & $6-4$ & 12 & $4-4$ & 12 & $2-4$ \\
\hline 13 & $10-5$ & 13 & 8-5 & 13 & $6-5$ & 13 & $4-5$ & 13 & $2-5$ \\
\hline 14 & $10-6$ & 14 & $8-6$ & 14 & $6-6$ & 14 & $4-6$ & 14 & $2-6$ \\
\hline 15 & $10-7$ & 15 & $8-7$ & 15 & $6-7$ & 15 & $4-7$ & 15 & $2-7$ \\
\hline 16 & $10-8$ & 16 & $8-8$ & 16 & $6-8$ & 16 & $4-8$ & 16 & $2-8$ \\
\hline
\end{tabular}


Appendix C

COMIMUNICATION PROTOCOLS 

format

Most message and data transfers between a UP and the OI have the following general

$$
\mid \text { STX } \mid \text { type } \mid \text { SPACE } \mid * * \text { data }^{* *} \mid \text { chksum | CR |, }
$$

where the STX, SPACE, and CR are standard ASCII characters. Type is a binary byte that tells the receiving computer what kind of information to expect in the data field. The data field can vary in length depending on the transfer type and is usually binary. The chksum is a 1-B sum of all bytes before chksum excluding the STX.

\section{Message and Data Transfers from the UP to the OI}

The exact message format can vary slightly from one type to another depending on what additional information must be included in the message. Table C.1 lists type numbers for data and message transfers from a UP to the OI. Some listed type numbers have not yet been reserved for a particular function. Some transfer types use other reserved numbers in the data

Table C.1. Type numbers for UP to OI transfers

\begin{tabular}{cl}
\hline Type \# & Operation \\
\hline $140-143$ & Time-data block, 1 of 4 \\
144 & Request acknowledge \\
145 & \\
146 & Cell Status \\
147 & Files copied \\
148 & \\
149 & \\
150 & Error number \\
\hline
\end{tabular}

position to further define a particular message or response. The following paragraphs provide a more complete description of the various message strings.

Cell Status uses the form

$$
\text { | STX | 146 | Space | DATA* | cksum | CR |, }
$$

where DATA is $72 \mathrm{~B}$, or $9 \mathrm{~B}$ for each of the eight stages. The $9 \mathrm{~B}$ for each stage are

$$
\text { | chan | stat | speed | amp | amp | rsmod | slpmod | flags | Space |. }
$$

The flags byte (Table C.2) carries information about any abnormal condition detected during the analysis process. Another four-bits set of condition flags called hflags (Table C.3) in the software is also sent as the upper nibble of stat. 
Table C.2. Flags byte interpretation

\begin{tabular}{cl}
\hline $\begin{array}{c}\text { Bit } \\
\text { position }\end{array}$ & \multicolumn{1}{c}{ Condition } \\
\hline 7 & Vibration alarm \\
6 & Vibration warn \\
5 & Surging \\
4 & Secondary \\
3 & Check motor \\
2 & Unused \\
1 & Unused \\
0 & Unused \\
\hline
\end{tabular}

Table C.3. Hflags byte interpretation

\begin{tabular}{cl}
\hline $\begin{array}{c}\text { Bit } \\
\text { Position }\end{array}$ & \multicolumn{1}{c}{ Condition } \\
\hline 3 & Input open \\
2 & Input shorted \\
1 & A/D over range \\
0 & Nonsynchronous \\
\hline
\end{tabular}

Request Acknowledge uses the form

| STX | 144 | Space | Req\# | CR |,

where Req\# is the same number that the OI request carried when it was sent to the UP. For more information about request numbers, refer to the section later in this appendix, Request Messages from the OI to the UP.

TDAT Return uses the form

| STX | 140-143 | Space | cell_stg | 2048 data bytes* | cksum | CR |,

where type is 140 for part zero, 141 for part one, etc., for each of the four parts.

Error Message uses the form

$$
\text { |STX | } 150 \text { | Space | err_num | CR |, }
$$

where err_num is an error number (Table C.4). 
Table C.4. Error condition codes

\begin{tabular}{cl}
\hline Number & \multicolumn{1}{c}{ Condition } \\
\hline 1 & A/D trigger error \\
2 & No disk in drive-A \\
3 & Write protected A: \\
4 & General disk access \\
5 & No files found \\
8 & Insufficient disk space \\
10 & No "init.dat" file \\
11 & No LDAS-16 board found \\
\hline
\end{tabular}

\section{Request Messages from the OI to the UP}

Most of the messages sent to a UP involve either a data request or a request for some desired UP operation. The basic format for such requests is

$$
\text { | STX | Type\# | Space | data_byte | CR |. }
$$

Table C.5 lists the type numbers currently used by the system software along with the significance or required content of the data byte.

Table C.5. Type numbers for OI to UP transfers

\begin{tabular}{clc}
\hline Type \# & Operation & Data byte \\
\hline 130 & Abort program & 'A' \\
131 & Time data request & cell_stg \\
132 & Save stage tdat to disk & cell_stg \\
134 & Save cell tdat to drive-A & cell\# \\
135 & Save Unit tdat to drive-A & unit\# \\
136 & Copy Event and Stat files to a: & \\
138 & Repeat Mode ON & cell\# \\
140 & Repeat Mode OFF & \\
\hline
\end{tabular}





\section{INTERNAL DISTRIBUTION}

1-5. K. N. Castleberry

6. G. T. Alley

7. B. G. Eads

8. R. A. Hess

9. J. M. Jansen

10. D. W. McDonald

11. G. N. Miller

12. J.D. White

13. R. E. Uhrig

14. J. O. Stiegler

15. D. A. Clayton

16. R. A. Kisner

17. S. F. Smith

18-21. J. W. Deck

22. C. J. Deffenbaugh

23. B. F. Deneve

24. J. M. Fitzgerald

25. M. L. Griffen

26. S. L. Gunn

27. C. F. Harley

28. C. H. Harper
29. M. M. Hibdon

30. G. F. Jones, Jr.

31. W. Landrum

32. M. A. Mack

33. E. D. Mittendorf

34. W. T. Price

35. G. E. Reynolds

36-39. D. W. Rigdon

40. C. W. Shockley

41. C. W. Sheward

42. T. M. Smith

43. J. J. Staley

44. K. D. Stratemeyer

45. D. L. Weishaar

46. D. L. Wilburn

47-48. Central Research Library

49. Y-12 Technical Reference Section

50-51. Laboratory Records

52. Laboratory Records-Record Copy

53. ORNL Patent Section

54. I\&C Division Publications Office

\section{EXTERNAL DISTRIBUTION}

50. L. Ewing, United States Enrichment Corporation, Two Democracy Center, 6903 Rockledge Drive, Bethesda, MD 20817

51. W. Jordan, United States Enrichment Corporation, Two Democracy Center, 6903 Rockledge Drive, Bethesda, MD 20817

52. Assistant Manager for Energy Research and Development, DOE-ORO, P.O. Box 2001, Oak Ridge, TN 37831-8600

53-54. Office of Scientific and Technical Information, U.S. Department of Energy, P.O. Box 62, Oak Ridge, TN 37831 
